Document downloaded from:

http://hdl.handle.net/10251/61730

This paper must be cited as:

Rinuado, P.; Paya-Zaforteza, I.; Calderón García, PA. (2016). Improving tunnel resilience against fires: A new methodology based on temperature monitoring. Tunnelling and Underground Space Technology. 52:71-84. doi:10.1016/j.tust.2015.11.021.

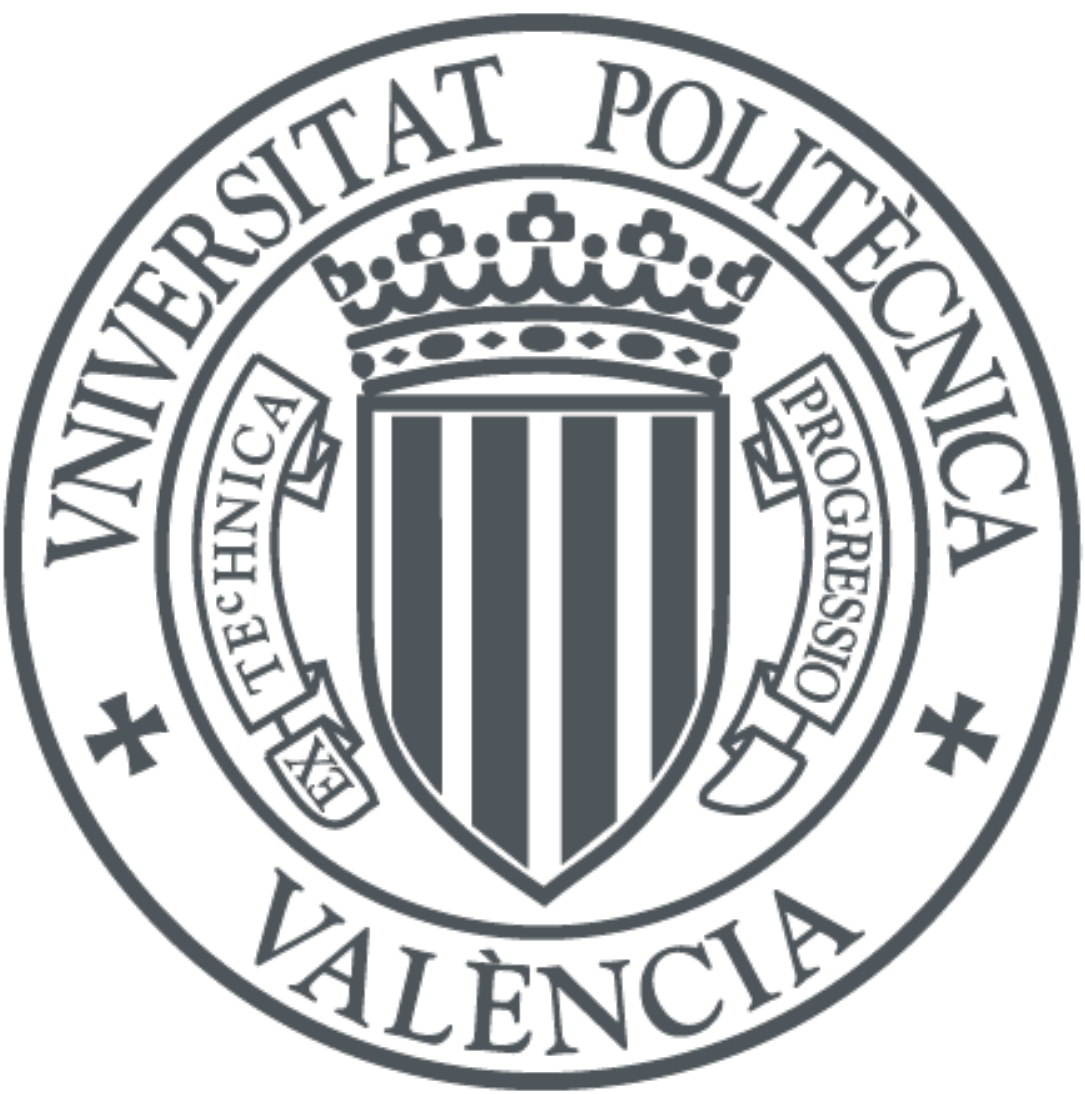

The final publication is available at

http://dx.doi.org/10.1016/j.tust.2015.11.021

Copyright Elsevier

Additional Information 


\section{This paper must be cited as:}

Rinaudo P., Paya-Zaforteza I., Calderón P.A.

Improving tunnel resilience against fires: A new methodology based on temperature monitoring (2016) Tunnelling and Underground Space Technology, 52, pp. 71-84.

DOI: $10.1016 /$ j.tust.2015.11.021

The final publication is available at:

http://dx.doi.org/10.1016/j.tust.2015.11.021

Copyright: Elsevier. 


\title{
Improving tunnel resilience against fires: a new methodology based on temperature monitoring
}

\author{
Paula Rinaudo, Ignacio Paya-Zaforteza*, Pedro A. Calderón
}

ICITECH, Universitat Politècnica de València, Camino de Vera s/n, 46022, Valencia, Spain.

Authors e-mail addresses:

\author{
Paula Rinaudo: $\quad$ pauri@posgrado.upv.es \\ Ignacio Paya-Zaforteza: igpaza@cst.upv.es \\ Pedro A. Calderon: pcaldero@cst.upv.es
}

\begin{abstract}
Monitoring temperatures during tunnel fires is of major importance for both the firefighters extinguishing the fire, and the engineers in charge of the subsequent repair work. However, current methods of assessing fire damage have limitations when applied to tunnels and only provide estimates of the maximum fire temperatures at specific locations of the tunnel. This is not a desirable situation, as the temperature-time curves associated with the fire event should be available for use in assessing the residual strength of the tunnel structure. This is the key parameter in defining repair work and the length of time the tunnel will need to be closed and thus the socio-economic cost of the tunnel fire. In addition, real-time recording of the temperature-time curves would provide valuable information to the firefighters engaged in extinguishing the fire.

This paper presents a new general methodology for the optimal placement of sensors in a tunnel to obtain the temperature evolution at any point along its lining during a fire. The methodology was applied to the Virgolo Tunnel in Italy, in which 100 potential high-temperature sensor configurations were tested and a set of optimal sensor configurations was proposed. The results of the analysis show that: (a) the proper location of the sensors is crucial; (b) it is possible to define a set of sensor configurations that minimize the cost of the monitoring system and maximize the accuracy of the estimated temperatures; (c) it is important to place at least three high-temperature sensors in each monitored cross section (at the crown and symmetrically on the haunches/side walls). The proposed methodology improves tunnel resilience against fires, as it enables safer infrastructure and a faster and more economic recovery of the tunnel after a fire event.
\end{abstract}

Keywords: Resilient design, Fire, tunnel, Structural Health Monitoring, multi-objective optimization.

* Corresponding author. Tel: +34 963877562; fax: +34 963877568

Email: igpaza@cst.upv.es 


\section{Introduction}

The fires that broke out in the Mont Blanc tunnel in 1999, in the St. Gotthard tunnel in 2001, the Burnlet tunnel in 2007 and the Wuxi Lihu tunnel in 2010 had catastrophic consequences in terms of loss of life and economic costs and aroused public interest in tunnel fire safety. They also gave rise to significant research in the field of tunnel fires (see e.g. Safe Tunnel 2005, FIT 2005, NCHRP 2011,Beard and Carvel 2012, Lai et al. 2014, Barbato et al. 2014and Ingason et al. 2015) with the aim of reducing fire risk in tunnels.

In the technical field of risk engineering, the term 'risk' is defined as the product of the probability of an event and the expected outcome - typically expressed as damage —of the event (Hardy, 2005). In the case of tunnel fires, adverse outcomes may include loss of life and injuries to victims, direct costs in the form of repairs and indirect costs in the form of loss of toll revenues and the economic impact on the region due to tunnel closure. To reduce fire risks, several prevention and protection measures have been developed to reduce the probability of tunnel fires, to ensure early fire detection and to keep loss of life and damage to a minimum (see Beard and Carvel, 2012). As regards the economic costs, the following aspects need to be considered:

- It is always cheaper to repair a tunnel after a fire than build a new one, since construction times and costs are higher if a new tunnel is built than if the tunnel is repaired (Corsi, 2008).

- Indirect costs due to tunnel closure after a fire are usually much higher than the direct costs associated with repairs (Corsi, 2008). For example, the 1996 fire in the Eurotunnel linking France and the United Kingdom was responsible for $€ 87$ million in repair work and $€ 211$ million in lost revenue (Peter, 2000).

Therefore, in order to reduce the cost of tunnel fires it is essential to reduce closure times. This can be achieved through better and faster assessment of damage to the structure, as this assessment specifies the areas in need of repair and the methods to be used. However, assessing fire damage in a tunnel is a challenging task, especially when concrete linings are used, as the assessment involves non-destructive or destructive techniques and estimating the temperature-time curves associated with the fire event to calculate the residual strength of the structure (Corsi, 2008). Yet, the application of non-destructive techniques in tunnels is limited due to the non-verticality of the tunnel walls and the roughness of the tunnel surfaces (Felicetti, 2013). In addition, these methods do not give any information about the intensity and duration of the fire and the temperature-time curves associated with it. These are key parameters in assessing the damage to the tunnel structure and obtaining them can be difficult, as has been reported by several authors (Niels et al. 2008, Calavera et al. 2005 and Wang et al. 2014).

Within this context, this paper proposes a new methodology to increase the resilience of tunnels against fires, i.e., to increase the capacity of tunnels to withstand fires with minimum losses and to recuperate a specific tunnel service level as fast as possible (see Bocchini et al., 2014 for a broad discussion on the resilience of civil infrastructure). The proposed methodology combines high-temperature sensors in certain sections of the tunnel with numerical models of different fire events to estimate the temperature-time curves imposed by a fire at any point on the tunnel surface. The methodology can be applied to both new and existing tunnels and provides optimal monitoring solutions, i.e., solutions that provide the maximum information at a minimum cost.

Section 2 of the paper contains a general description of the method, Section 3 validates the method with a case study on the Virgolo tunnel, and Section 4 details the main conclusions of the research carried out.

\section{Methodology}

The aim of this paper is to present a monitoring strategy that increases the resilience of tunnels against fires. Defining this monitoring strategy involves: (a) designing the sensor network, i.e. deciding on the sensor layout; (b) defining the data treatment, i.e. the information to be obtained from the raw sensor data; and (c) evaluating the total cost of the system. As there are an infinite number of sensor configurations, the monitoring problem also has infinite solutions, so that the final choice depends on the characteristics of the 
tunnel under study (geometry, importance, traffic, etc.) and any financial or political constraints. The general procedure for defining monitoring strategy can be divided into the following steps:

1. Step 1. Data collection. First of all, all the available data on the tunnel under study should be gathered and analyzed. This should include the tunnel geometry (type of cross section, dimensions, length, etc.), the materials and fire protection used, existing firefighting protocols, ventilation systems and the characteristics of the traffic going through the tunnel.

2. Step 2. Definition of possible fire scenarios. Defining fire scenarios involves determining: fire load, characterized by its location in the tunnel, its size and Heat Release Rate (HRR) as a function of time. The HRR is the rate at which heat is generated by fire. If there is no traffic restriction, the nine fire scenarios proposed by Inganson (2006) can be used as the starting point.

3. Step 3. Numerical modeling of fire scenarios. Models of the most critical fire scenarios are built using Computational Fluid Dynamics (CFD) techniques. CFDs models can be built with different software packages. In this study we used the Fire Dynamic Simulator software (FDS henceforth) (Mc Grattan, 2010), developed at the National Institute of Standards and Technology (NIST) in the USA. To build a CFD model with FDS we must define: (1) a control volume with its boundary conditions representing the volume for which the entire analysis is carried out; (2) the geometry included in the control volume which represents the geometry of the case study; (3) a mesh or discretization of the control volume; (4) material properties (conductivity, density, specific heat and emissivity); (5) fire sources; (6) a combustion model; and (7) the outputs of the model. FDS can provide several outputs, such as gas temperatures, gas velocity and smoke density. In the monitoring strategy presented in this paper, temperatures are the outputs of the CFD models as they are aimed at providing the evolution of gas temperatures with time for each fire scenario at specific points in the tunnel.

4. Step 4. Proposal of temperature sensor configurations. In the proposed monitoring strategy, temperature sensors such as high temperature thermocouples or the high temperature fiber optic sensors developed by Rinaudo et al. (2015a) are located near the internal surface of the tunnel at equidistant cross sections. To define a sensor configuration, the following parameters need to be established: the number $N_{x}$ of monitored cross sections and their separation $n_{x}$, the number $N_{y}$ of sensors placed at each monitored cross section, and the location of these $N_{y}$ sensors within each monitored cross section. Fig. 1 shows an example of a sensor configuration in which six cross sections are monitored by five sensors arranged as displayed in Fig. 1c. It should be remembered that sensor layout is a key parameter, since for each number of sensors many different configurations are possible and each one will have a specific performance and cost.

5. Step 5. Assessment of the performance of each proposed sensor configuration. For this, it is assumed that CFD models predict accurate values of the temperature-time curves at all points in the tunnel and for each fire scenario considered. The basic assessment procedure has two steps:

5.1 Calculation of temperatures in a grid of points ("interpolation grid" henceforth) close to the tunnel surface. Using different interpolation techniques, the temperatures in the grid shown in Fig. 1 are obtained for each fire scenario using the temperatures at the sensor locations as input data. To simplify this process, the tunnel surface is unrolled to transform the 3D coordinate system $(x, y, z)$ to a $2-D$ coordinate system $\left(x, y^{*}\right)$ as shown in Fig. $1 b$.

5.2 Definition and evaluation of error indexes and selection of an interpolation technique. For each interpolation technique and fire scenario and every point on the grid, the temperatures obtained by interpolation are compared to those obtained by the CFD models. This comparison provides the values of the error indexes that measure the overall error associated with each interpolation technique. The interpolation technique with the smallest error is then selected as the best technique to estimate fire temperatures.

6. Step 6. Comparison of error indexes versus cost. Sensor configurations are compared as regards their precision (error indexes) and cost (measured indirectly through the total number of sensors in 
the configuration), after which a set of optimal monitoring configurations is proposed. Note that a set of solutions and not a single solution is obtained since a multi-objective evaluation (precision versus cost) is carried out.

The above mentioned steps are explained in detail in Section 3, when the method is applied to the Virgolo Tunnel as a case study.

\section{Case study: the Virgolo Tunnel}

\subsection{Introduction.}

The Virgolo road tunnel is on the Brennero highway near Bolzano in northern Italy. It has two tubes with two lanes per tube and a total length of $860 \mathrm{~m}$. It has a horse-shoe cross section with reinforced concrete linings, as shown in Fig. 2. The cross section is $6.5 \mathrm{~m}$ high, $10 \mathrm{~m}$ wide, with an area of $54 \mathrm{~m}^{2}$. The tunnel has a $1 \%$ gradient and is almost completely straight with no sharp curves. According to Kelly (2008), an average of 9300 vehicles pass through it daily, $10 \%$ of these being heavy goods vehicles (HGV) and $2.5 \%$ carry dangerous goods. The tunnel has a radio communications system, telephones and fire extinguishers. However, it is not equipped with forced ventilation or a fire warning system.

This tunnel was the subject of several fire tests within the framework of the European UPTUN Project (cost effective, sustainable and innovative upgrading methods for fire Safety in existing tunnels). Detailed information on these tests can be found in Bergmeister (2006). The results from these tests were analyzed in detail by Rinaudo et. al (2015b), who also developed and validated a CFD model to explain the tunnel's response to fires. This CFD model will be used in the following sections to define the monitoring strategy proposed in this paper.

\subsection{Fire scenarios}

Fire scenarios are defined by their HRR curves, the size of the fire loads and by the position of the fire loads in the tunnel. In this study, nine different HRR curves for different types of road vehicles were considered in accordance with the recommendations of Opstad et al. (2006), Inganson (2006) and Caliendo et al.(2012). These curves represent fire events ranging from a small fire in a car to a severe blaze caused for example by a tanker.

Fig.3a shows a typical proposed HRR curve along with its defining parameters. The HRR curve has three phases: an initial linear fire growth phase, a steady state phase, and a final phase of linear fire decay. The linear growth is defined by the slope $\alpha_{g, L}$ of the straight line that represents it. The steady state phase is defined by the value of the peak $\operatorname{HRR} Q_{P}$, and the decay phase is defined by the slope $\alpha_{D, L}$ of the straight line that represents it. Table 1 details the fire scenarios, the main values defining the HRR curves and fire load sizes used in this study; $\alpha_{g, L}$ is equal to $10 \mathrm{MW} / \mathrm{min}$ for $Q_{P}$ up to $30 \mathrm{MW}$ and equal to $20 \mathrm{MW} / \mathrm{min}$ for $Q_{P}$ higher than $30 \mathrm{MW}$. The time $t_{D}$ of beginning of the decay phase and the total duration of the fire $t_{d}$ are based on the French recommendations (PIAC, 1999). Finally, the time $t_{\max }$ to reach $Q_{P}$ can be obtained with Eq. 1:

$t_{\max }=\frac{Q_{p}}{\alpha_{g, L}}$

Eq. 1

In the CFD analyses all the fire loads were located in the middle section of the tunnel, i.e., the cross section with $x$ coordinate equal to $430 \mathrm{~m}$. Two fire positions were considered for each HRR curve: one in which the fire sources were centered at the cross section, and another with fire sources centered in a traffic lane, so that a total of 18 CFD models were built. These models simulated a 30-minute fire duration, after which time it was assumed that the firefighting service would intervene. This 30 minute duration results in a steady state phase of fully developed fires of between 20 and 29.5 minutes, according to the type of fire source. Figure $3 \mathrm{~b}$ shows the resulting HRR curves. 
In addition, for each sensor configuration and fire scenario, two possible fire load locations were considered with respect to the relative position of the fire load and the monitoring system (Fig.4). The first considers the most favorable scenario from the point of view of the monitoring system, in which the fire occurs in a monitored cross section. The second is the most unfavorable scenario, with the fire midway between two monitored cross sections.

\subsection{Computational Fluid Dynamic Models}

Advanced Computational Fluid Dynamic (CFD) models were developed to simulate the fire scenarios in the tunnel. FDS software (McGrattan et al.2010) was chosen to model the fire event because it has been widely tested on tunnel fires (see for example the works of McGrattan (2006) and Cheong et al. (2009)). The software solves numerically a large eddy simulation form of the Navier-Stokes equations with the emphasis on smoke and heat transport.

The sensitivity analysis performed showed that the entire tunnel structure had to be included in the model. As a consequence a control volume measuring $10.2 \times 7 \times 860 \mathrm{~m}$ was defined. The longitudinal axis of the tunnel corresponds to the $x$ axis of the FDS model, and the section with the $x$ coordinate equal to 0 is located at the tunnel's midway point. Different combinations of meshes and cell sizes were studied to define a mesh with cell sizes small enough to properly model the fire but coarse enough to run the model efficiently. The $470 \mathrm{~m}$ long central part of the tunnel was modeled with cells measuring $0.2 \times 0.2 \times 0.2 \mathrm{~m}$, and cells measuring $0.4 \times 0.2 \times 0.2 \mathrm{~m}$ were used for the rest of the tunnel. The resulting number of parallelepiped cells in the control volume was $5,099,400$.

Fig. 5 shows the geometry of the model. Since it is not possible to construct a curved geometry in FDS, the tunnel cross section was defined using rectangular obstructions and the "saw tooth" option was used to prevent vortices from being generated at the sharp corners (McGrattan, 2010). The direction of gravity was modified in the model to include the tunnel's $1 \%$ gradient.

An initial temperature of $20^{\circ} \mathrm{C}$ throughout the tunnel was set at the beginning of all the fire simulations. The two tunnel ends were defined as FDS open boundary conditions. Concrete material with thermal properties according to Eurocode2 (CEN-EN 2-1-1, 2004) was assigned to all tunnel linings.

The perimeter of the tunnel cross section was divided into segments measuring $1.04 \mathrm{~m}$ along the perimeter, resulting in 17 equidistant points with an angle of $12^{\circ}$, as shown in Fig. 6 . At each of these points, FDS gas temperature measuring devices ("sensors" in FDS terminology) were placed at a distance of $0.05 \mathrm{~m}$ from the tunnel intrados. This FDS sensor layout was repeated every meter in the longitudinal direction, giving a total of 14,603 devices (17x859) and defined a grid similar to the one shown in Fig. 1c.

The fire load was modeled using the mixture fraction combustion model proposed by FDS (McGrattan, 2010). The fire sources were modeled as a rectangular obstruction with a burner on the upper surface. The dimension of the obstruction was defined for each fire model according to Table 1. For each model a heat release rate per unit area (HRRPUA) was defined dividing the peak HRR by its corresponding burning area. The curves increase linearly from 0 to their maximum values (HRRPUA $A_{\text {MAX }}$ ) in $t_{\max }$ and remained constant until $t_{D}$.

All the FDS models were run as an MPI parallel job on a cluster for massively parallel processing, which consists of 72 nodes. The nodes in the cluster were BX920S3 Fujitsu on a BX900S2 blade chassis. Each node of the chassis had two Intel Xeon E5-2450 8c / 16T and 64 GB / RAM DDR3 (ratio 4GB / core). The resources assigned were 13 cores and 8 GB RAM per core. A typical simulation took between 66 and 112 hours depending on the fire size. Gas temperatures, obtained from a grid of 14,603 points similar to the one displayed in Fig. 1c were retained as the output of the FDS analyses.

\subsection{Temperature sensor configurations considered.}


Typical fire detection systems in tunnels, such as linear heat detection systems, are usually installed close to the intrados of the tunnel and/or at the mid-height of the lateral walls. These configurations might work properly to detect the beginning of a fire, but, as this study will show, a detailed analysis is required to define the number and layout of the sensors needed to get an adequate estimation of the temperature-time curves in a tunnel lining resulting from a fire event. The definition of these curves is critical, because: (a) they provide information that enables firefighters to work more safely, and (b) enable proper estimation of the damage to the tunnel and proper definition of any required repair work, which in turn means shorter times for re-opening a tunnel after a fire.

Defining a sensor configuration involves establishing: (a) the number of sensors $N_{y}$ in each monitored cross section; (b) the layout of the sensors in the tunnel monitored cross section; and (c) the distance $n_{x}$ along the longitudinal axis of the tunnel between two consecutive monitored cross sections. Configurations with a number of sensors $N_{y}$ of between three and seven, and with longitudinal separation $n_{x}$ of $5,10,15$ and $20 \mathrm{~m}$ were considered in this study. The proposed configurations are divided into 20 groups. These groups are a combination of the five possible values of the number of sensors with the four possible separation values along the length of the tunnel. For each group, five different sensor layouts cross section (see Fig. 7) were considered, which resulted in a total of 100 different sensor configurations. The layout of the sensors within the cross section was based on two considerations: i) the points at which fires reached the maximum temperatures, and ii) the points that provide critical information for the interpolation methods.

Each configuration was identified according to the sensor layout in the cross section and the longitudinal separation between sensors. For example the configuration with three sensors in the cross section, located at points "c", "k" and "r" in Fig. 7, and with a longitudinal separation $n_{x}$ of $5 \mathrm{~m}$ is labeled "ckr 5". Fig. 7 shows the 25 basic sensor configurations studied.

\subsection{Interpolation methods}

Each FDS model of a fire event provides temperatures as a function of time at each point on a grid of 14,603 points, similar to the one shown in Fig. $1 \mathrm{c}$ and including the full tunnel length. These temperatures are called true temperatures henceforth, because the analysis assumes that they perfectly match the temperatures in the tunnel caused by the fire event. Fig. 8 shows an example of the true temperatures for a fire in a heavy goods vehicle (scenario HRR 100) at the center of the central cross section of the tunnel 15 min after the start of the fire. Fig. 8 a shows a 3D representation of the true temperatures in the central $200 \mathrm{~m}$ of the tunnel. Fig. $8 \mathrm{~b}$ and Fig, $8 \mathrm{c}$ plot the temperatures in the tunnel central cross section and in a $200 \mathrm{~m}$ longitudinal section respectively.

However, as temperature sensors are placed at specific points in the tunnel, estimating the temperature-time curves at any given point involves interpolating the temperatures measured by a specific sensor configuration. This study tested five exact interpolation methods. The term "exact" means that the temperatures predicted by the interpolation method at the sensor positions are equal to the temperatures actually measured by the sensors. These five methods are (Moler, 2008 and Bohling, 2005):

- Piecewise linear interpolation, which connects known temperature points with straight lines and then uses these lines to interpolate the temperatures at any point.

- Nearest neighbor interpolation, which assigns to each point the temperature measured by the nearest sensor.

- Piecewise cubic hermite interpolation, which is similar to the piecewise linear interpolation but using a third order polynomial function that preserves the shape of the data (measured temperatures) as interpolation functions.

- Cubic spline interpolation, which use cubic splines with continuous second derivate as interpolation functions.

- Kriging interpolation method, which is based on regression against observed values of surrounding data points, weighted according to spatial covariance values.

The first four methods are deterministic, i.e. they do not provide any estimation of possible errors, while the Kriging is stochastic, i.e., it gives an estimation of the errors. 
All the interpolation methods were applied using Matlab functions (Matlab 2011a). For piecewise linear, nearest neighbor, piecewise cubic hermite and cubic spline methods (henceforth, Linear, Nearest, Cubic and Spline); the interp2 function (Moler, 2008) was used and the Matlab toolbox DACE (Lophavenet at. 2002) was used to apply the Kriging method. This method was applied using a zero order polynomial regression function and a cubic spline correlation function. Two sets of values were assigned to the correlation functions, resulting in two variants known as Kriging A and Kriging B. Fig. 9 shows an example of the temperatures estimated by all the interpolation methods for the HRR 100 fire scenario (fire in a heavy goods vehicle) $15 \mathrm{~min}$ after the beginning of the fire at the center of the tunnel central cross section, at the midpoint between two sections monitored with the "ckr20" sensor configuration.

The performance of the interpolation methods was assessed by the error indexes defined in Section 3.6. When several methods had a similar error index, the computing time required to perform the interpolation was the second selection criterion for the best interpolation method. According to this last criteria, the best method was the nearest neighbor interpolation, followed by the cubic spline interpolation, the Kriging, the piecewise linear interpolation and the cubic interpolation.

\subsection{Assessment of the interpolation methods}

Different interpolation methods can be assessed by evaluating their errors, these being defined based on the differences between the temperatures estimated by interpolation and the true temperatures. As the temperatures are interpolated on a point grid similar to the one shown in Fig. 1, the errors of each interpolation method are defined by a matrix in which each component represents the error at a given point of the interpolation grid. In addition, the matrix components change with time, as both the true and the measured temperatures are a function of time. However, it is advisable to reduce all the errors to a single scalar value to facilitate the comparison of the interpolation methods.

The mean absolute error (MAE) and the root mean square error (RMSE) were chosen to summarize the error matrix into a scalar. MAE provides an average of the absolute differences between the estimated temperatures and the true temperatures, while RMSE represents the standard deviation of this difference. Both MAE and RMSE are widely used in academic research. Previous applications include, for instance, the evaluation of air temperature interpolations (see e.g. Willmott et al. (2006), Saz-Sánchez et al. (2010)). These errors are defined in Eq. 2 and Eq. 3 and have units of ${ }^{\circ} \mathrm{C}$ :
$\operatorname{MAE}=\frac{1}{\mathrm{n}} \sum_{\mathrm{i}=1}^{\mathrm{n}}\left|\mathrm{T}_{\mathrm{est}_{\mathrm{i}}}-\mathrm{T}_{\text {true }_{\mathrm{i}}}\right|$
Eq. 2
RMSE $=\sqrt{\frac{1}{n} \sum_{\mathrm{i}=1}^{\mathrm{n}}\left(\mathrm{T}_{\mathrm{est}}-\mathrm{T}_{\text {true }_{\mathrm{i}}}\right)^{2}}$
Eq. 3

Where $\mathrm{T}_{\text {est }}$ is the estimated temperature for point $i, T_{\text {true }_{i}}$ is the true temperature for point $i$ and $n$ is the number of points on the interpolation grid. Since the fire is at the mid-point of the tunnel and the maximum temperatures, and consequently the maximum differences between the interpolated and true temperatures are near the fire, a distance of $200 \mathrm{~m}$ was considered to calculate the errors, which gave a value of $n$ equal to 3400 points. To obtain errors which were not time-dependent, and considering that 600 s after the start of the fire all the FDS models were in the steady-state phase, the average of the errors from 600 s to 1800 s was chosen.

In addition, and from the engineering point of view, it is important to minimize the relative error in the areas where the temperatures are higher than $300^{\circ} \mathrm{C}$ and $600^{\circ} \mathrm{C}$. The former is the temperature at which concrete starts to experience a significant loss of compressive strength, and the latter is the temperature at which concrete loses all its structural strength (Concrete Society 2008). Two further error indexes were thus defined: mean absolute error of the relative error for points with a true temperature higher than $300^{\circ} \mathrm{C}$ ( $M A E(R E 300))$ and mean absolute error of the relative error for points with a true temperature higher than $600^{\circ} \mathrm{C}$ (MAE(RE600)). Equations 4 and 5 provide the expressions for these error indexes. 
$\operatorname{MAE}(\mathrm{RE} 600)=\frac{1}{\mathrm{n}_{600}} \sum_{\mathrm{i}=1}^{\mathrm{n}_{600}}\left|\frac{\mathrm{T}_{\text {est }_{\mathrm{i}}}-\mathrm{T}_{\text {true }_{\mathrm{i}}}}{\mathrm{T}_{\text {true }_{\mathrm{i}}}}\right|$

Eq. 5

Where $n_{300}$ and $n_{600}$ are the number of points with a true temperature higher than 300 and $600^{\circ} \mathrm{C}$, respectively.

As the interpolation method that gives the best results can vary with the sensor configuration, the six interpolation methods proposed were assessed according to the error indexes defined by Eq. 2 to Eq., 5 considering the nine fire loads in Table 1, two different positions of the fire load in the tunnel cross section, and two relative positions between fire and sensors, so that 36 different values of each error index were obtained for each sensor configuration.

The error indexes associated with each interpolation method were represented by box-and-whisker plots (see Fig. 10 for an example related to the configuration "clmr5"). The central red line in each plot represents the median of the error index of the interpolation method analyzed; the lower and upper blue lines represent the first and third quartiles respectively of the data represented. The distance between the first and third quartiles is known as the interquartile range, and the dashed black lines are the whiskers, which extend to the most extreme data points not considered outliers. The outlier values, which are represented as small red crosses, are further than 1.5 times the interquartile range. The plots in Fig. 10 show that the "cubic" and "spline" interpolation methods have the lowest errors of all the error indexes defined. However, these boxand-whisker plots do not show whether or not the differences are statistically significant.

The Kruskal-Wallis test (Stephens and Murray 2002), which is a nonparametric version of the one-way ANOVA, was used for each error index to determine whether any interpolation method was significantly different from the others. For example, this test found that there were significant differences among the interpolation methods for the 'clmr5' configuration. Multiple comparison tests (Stephens and Murray 2002) were then done to determine the methods with significant differences.

The results showed that for the RMSE and the MAE, the "nearest" method had significant differences with the "Cubic" and "Spline" methods. For the MAE(RE300) and the MAE(RE600), the "Cubic" and "Spline" methods presented significant differences from the rest of the methods, but did not differ significantly from each other. According to these results, specific to this sensor configuration, "Spline" was the best interpolation method, as it was significantly better than the "nearest" and had lower computing times than the "Cubic".

This procedure was repeated for all the sensor configurations and it was found that the "Nearest interpolation method" always had significant differences from the others, especially for the MAE(RE300) and MAE(RE600) error indexes. Kriging methods improved their results in configurations with larger numbers of sensors, but they were never significantly better than the Spline or Cubic methods. Accordingly, the Spline method was chosen as the best interpolation method for all sensor configurations because of its shorter computing times (it had the second lowest computing times after Nearest).

\subsection{Selecting the best sensor distribution for each group}

The aim of this step was to select the configurations with the best sensor layout for a given number of sensors in a cross section and a given separation between the monitored cross sections. In the case under study, as explained in Section 3.4 and Fig. 7, 20 groups of five sensor layouts were analyzed. 
In order to find the sensor configuration of each group that minimizes the errors for most of the fire events considered, the error indexes associated with each configuration were plotted against the fire scenarios. It is important to highlight that for each configuration and for each value of HRR, four points had to be plotted, as there were two possible fire locations within the tunnel cross section and two possible relative positions between sensors and fire. As an example, Fig. 11 shows the results for configurations with three sensors in the cross section and a longitudinal separation of $5 \mathrm{~m}$.

The following comments can be made on these results:

- RMSE and MAE increase with HRR, whereas MAE(RE300) and MAE(RE600) tend to decrease with HRR. This is because the number of temperature values used to obtain RMSE and MAE is always the same and does not depend on HRR. However, the number of temperature values used to obtain MAE(RE300) and MAE(RE600) increases with HRR because higher HRRs produce higher temperatures in the tunnel. This means an increase in the number of values used to calculate $\operatorname{MAE}(\mathrm{RE} 300)$ and $M A E(R E 600)$. Consequently, according to Eqs. 4 and 5, there is a tendency for these error indexes to decrease. This pattern was observed in all the configurations analyzed.

- Some configurations ("fko 5" for example) show much better behavior when the MAE(RE300) and MAE(RE600) indexes are analyzed than when RMSE and MAE are considered. This could appear contradictory, but is explained by the fact that for these configurations the highest differences between the estimated and the true temperatures occur at points on the interpolation grid where temperatures are lower than $300^{\circ} \mathrm{C}$ and these points are not used to calculate $M A E(R E 300)$ and $\operatorname{MAE}(\mathrm{RE} 600)$.

- The lowest RMSE values are obtained when the sensors are located according to the "ckr5" configuration. In this case, the errors vary between 7.5 and $91.8^{\circ} \mathrm{C}$, according to the HRR. The values of the RMSE vary between 6.58 and $112.3^{\circ} \mathrm{C}$ for the "dkq 5 " configuration, between 10.39and $109.2^{\circ} \mathrm{C}$ for "bks 5 ", between 9.3 and $137.7^{\circ} \mathrm{C}$ for "ekp 5 ", and between 12.76 and $146.2^{\circ} \mathrm{C}$ for "fko $5^{\text {". }}$

- MAE errors show minor differences among the sensors layouts, with "ckr 5", "dkq 5" and"ekp 5" showing similar values. The maximum MAE for these configurations is $55.2^{\circ} \mathrm{C}, 51.5^{\circ} \mathrm{C}$ and $56.2^{\circ} \mathrm{C}$, respectively.

- The values of $\operatorname{MAE}(\mathrm{RE} 300)$ are similar in all cases. The "bks 5" has the highest MAE(RE300) variation (values between $4.3 \%$ and $20.5 \%$ ). The "fko 5 " has the smallest MAE(RE300) variation (values between $4.5 \%$ and $10.4 \%$ ). MAE(RE300) values vary between $4.5 \%$ and $17.5 \%$ and between $4.9 \%$ to $17.1 \%$ in the "ckr 5 " and "dkq 5" configurations, respectively. It should be noted that MAE(RE300) starts with $H R R=20$ and $M A E(R E 600)$ starts with $H R R=50$, as lower HRRs do not generate temperatures higher than $300^{\circ} \mathrm{C}$ and $600^{\circ} \mathrm{C}$.

- Values of $\operatorname{MAE}(\mathrm{RE} 600)$ present even smaller variations: again, "bqs 5" is the configuration with the highest errors (between $5.6 \%$ and $13.5 \%$ ) and "fko 5 " the one with lowest values (between $2.9 \%$ and $10.7 \%$ ). The error for "ckr 5" and "dkq 5" varies between $6.2 \%$ and $12.7 \%$ and between $3.6 \%$ and $11.4 \%$, respectively.

- Finally the "ckr 5" configuration was selected because in most cases it had the lowest RMSE and MAE. It should be pointed out that this configuration did not give the best results when the $M A E(R E 300)$ and $M A E(R E 600)$ indexes were considered, but the difference with the minimum values of the $\operatorname{MAE}(\mathrm{RE} 300)$ and $\mathrm{MAE}(\mathrm{RE} 600)$ are small as compared to the differences in RMSE and MAE.

A process similar to the one described above was carried out for all 20 sensor groups. Tables 4,5 and 6 show the selected configurations, as well as the maximum values of RMSE, MAE, MAE(RE300) and $M A E(R E 600)$ for each HRR. The configurations are ordered in the table according to the number of sensors required to monitor the total tunnel length. 


\subsection{Optimal configurations and Pareto fronts}

Finally, a comparison is made of the sensor configurations' precision (error indexes) and number of sensors, after which a set of optimal monitoring configurations are proposed. The number of sensors is chosen as the comparison parameter because it is related to the cost of the monitoring system. Solutions are compared using the Pareto optimality criterion widely used in multi-objective optimization (see Payá et al. (2008) for an example).

Figs. 12 to 15 plot the maximum values of each error index against the total number of sensors of each configuration included in Tables 2 to 4 for HRR values equal to 100,150 and $200 \mathrm{MW}$. The results for the other six HRR values considered follow the same pattern and are not included in the figures for the sake of clarity. To find the sensor configurations that minimize both errors and total sensors, the Pareto front is obtained for each HRR. This front is drawn by joining the Pareto optimal configurations which are those that cannot be improved in one of the objectives without degrading the other. The configurations that are not inside the Pareto front are discarded, as there are others which provide a better estimation of the temperatures with fewer sensors. Note that for each value of HRR and $N y$, four values of the error indexes are plotted in each figure. These are the values of the distances $n_{x}$ of $5,10,15$ and $20 \mathrm{~m}$ between the monitored cross sections.

The number of times that each configuration in Tables 2 to 4 was included in the Pareto front was expressed as a percentage. For example, the configuration "cfkor 20 " was inside the Pareto front 18 times and outside 12 times, and so was Pareto optimal in $60 \%$ of the cases. The higher this percentage is, the better the configuration. These results were represented in the bubble chart in Fig. 16. In this graphic, the sensor configurations which had a better performance (were Pareto optimal in at least $70 \%$ of the cases) have been included.

From the results given in Tables 2 to 4 , and Figs. 12 to 16 it can be seen that:

- According to the Pareto fronts, increasing the number of sensors up to a maximum of 400 significantly reduces the error index values. The error reduction is smaller when total sensors reach 600 and is almost negligible when this figure is exceeded. The best configurations using a number of sensors close to 400 and to 600 sensors are the "cfkor 10" and the "bdhknqs 10 ".

- The temperature estimation errors can vary significantly according to the sensor configuration chosen. For example, both "ckr 10" and "ceimpr 20" have 258 sensors, but "ckr 10" has smaller errors than "'ceimpr 20". For example, with HRR equal to $70 \mathrm{MW}$, the error differences are $34.2 \%$, $19.9 \%, 39.4 \%$ and $29.4 \%$ for the RMSE, MAE, MAE(RE300) and MAE(RE600), respectively. This indicates that defining the location of the sensors deserves a lot of attention.

- In cases where a only a small number of sensors can be installed, the "ckr 20 ", "ckr 15" or "ckr 10" configurations should be used, as they are Pareto optimal in $100 \%, 100 \%$ and $70 \%$ of the cases. These configurations use 129, 171 and 258 sensors, respectively, and have a sensor at the crown of the tunnel (position " $k$ ") and two sensors around $2 \mathrm{~m}$. above the paved surface (sensors " $\mathrm{c}$ " and " $\mathrm{r}$ ").

- When a large number of sensors can be installed, "bdhknqs 5" (1204 sensors) and especially "bdhknqs 10" (602 sensors) should be considered as they are Pareto optimal in a very high percentage of the cases analyzed.

- It is important to place a sensor at the crown of the tunnel (sensor ' $\mathrm{k}$ ' in Fig. 6). This is the part of the cross section with the highest $z$ coordinate and is where hot gases accumulate and the highest temperatures are reached. In Fig. 16 it can be seen that all the best configurations include a sensor at this point, and that the configurations in which it is lacking $\left(N_{y}=4\right.$ and $\left.N_{y}=6\right)$ are much less likely to be a part of the Pareto fronts. 
The final selection of the sensor configuration depends to a large extent on financial considerations and the importance of the tunnel for traffic flow, both of which will define the error that can be assumed.

\section{Conclusions}

Monitoring temperatures during a tunnel fire is of major importance to improve tunnel resilience, as it can provide valuable information to firefighters during the fire event and to engineers in charge of tunnel damage assessment and repair work. The proper definition of this work is essential, as it can have a big impact on direct and indirect costs and traffic disruptions.

However, the current methods commonly used in assessing fire damage have limitations when applied to tunnels and only provide estimates of the maximum temperatures caused by the fire at specific points. As several authors have pointed out, this is not a desirable situation as there is a need to know the temperature evolution and maximum temperatures at all points in the tunnel.

In this context, this paper presents a new method for the optimal placement of high temperature sensors in a tunnel that makes it possible to obtain temperature evolution with time at any point of the tunnel lining. The method was applied to the case of the Virgolo Tunnel in Italy, where one hundred potential high temperature sensor configurations were examined and a set of optimal sensor configurations were proposed. The results of the analysis show that:

- Proper location of the sensors is crucial, as different sensor configurations with the same number of sensors give widely differing temperature estimation accuracy.

- The Pareto optimality criterion was used to define a set of sensor configurations that minimize monitoring costs while maximizing temperature estimation accuracy.

- It is important to place at least three high temperature sensors in each monitored cross section. These sensors should be located at the crown and symmetrically on the haunches or side walls of the tunnel.

- There is a threshold value that defines the reasonable maximum number of high temperature sensors to be placed in a tunnel. This value was found to be close to 600 sensors in the case study analyzed in this paper. Using a higher number of sensors increases the cost of the monitoring system without significantly improving the quality of the temperature estimates.

- The recommended sensor configurations are able to estimate the temperatures along the tunnel with a high accuracy. For example, the "cfkor $10^{\circ}$ configuration which uses 430 sensors has the following error indexes: RMSE between 7.4 and $71.7^{\circ} \mathrm{C}$, MAE between 4.2 and $37^{\circ} \mathrm{C}, \mathrm{MAE}(\mathrm{RE} 300)$ between 5.5 and $10.7 \%$ and $\operatorname{MAE}(\operatorname{RE} 600)$ between 4.8 and $14.9 \%$. The error indexes for the "bdhknqs 10 ", which uses 602 sensors, are: RMSE between 6.2 and $55^{\circ} \mathrm{C}$, MAE between 3.1 and $26.5^{\circ} \mathrm{C}$, MAE(RE300) between 3.4 and $9.5 \%$ and $\operatorname{MAE}($ RE600) between 3.8 and $15.9 \%$.

\section{Acknowledgments}

This work has been possible thanks to the financial support of the Spanish Ministry of Science and Innovation (Research Project BIA 2011-27104). Funding for this research was provided to Paula Rinaudo by the European Commission (Project Erasmus Mundus Action 2 ARCOIRIS). The authors are also grateful to Eduardo Cassiraga from the Universitat Politècnica de València and to Eduardo Loma Ossorio for all the support provided.

\section{References}


Barbato L., Cascetta F., Musto M. and Rotondo G., 2014."Fire safety investigation for road tunnel ventilation systems-An overview."Tunnelling and Underground Space Technology, 43, 253-265.

Beard A. and Carvel R., 2012. eds. The handbook of tunnel fire safety. 2 nd edition, ICE Publishing, doi: $10.1680 /$ htfs. 41530

Bergmeister K., 2006. "Real scale tunnel fire test Virgl/Virgolo tunnel", UPTUN Workpackage 6 Fire effects and tunnel performance: system response D62.

Bocchini, P., Frangopol, D.M., Ummenhofer, T., Zinke, T, 2014. "Resilience and sustainability of civil infrastructure: Toward a unified approach." Journal of Infrastructure Systems, 20 (2). DOI:

10.1061/(ASCE)IS.1943-555X.0000177

Bohling G., 2005. "Kriging." Kansas Geological Survey, Tech. Rep.

Calavera J., Gonzáles Valle E., Cano J. L., Díaz Lozano J., Fernández-Gomez J., Ley J. and Izquierdo J. M., 2005. Fire in the Windsor building, Madrid. Survey of the fire resistance and residual bearing capacity of the structure after the fire., INTEMAC.

Caliendo C., Ciambelli P., De Guglielmo M. L., Meo M. G. and Russo P., 2012. "Numerical simulation of different HGV fire scenarios in curved bi-directional road tunnels and safety evaluation." Tunnelling and Underground Space Technology, 31, 33-50.

CEN-EN 2-1-1, 2004."Eurocode 2: Design of concrete structures - Part 1-1: General rules and rules for buildings.",ComitéEuropéen de Normalisation,

Cheong M. K., Spearpoint M. J. and Fleischmann C. M., 2009. "Calibrating an FDS simulation of goodsvehicle fire growth in a tunnel using the runehamar experiment", Journal of Fire Protection Engineering, 19 (3), 177-196.

Concrete Society, 2008. "Assessment, design and repair of fire-damaged concrete structures", Concrete Society Working Group, Tech. Rep. 68.

Corsi F., 2008. "Damage to concrete in tunnels after fire exposure - evaluation report", UPTUN, Workpackage 4 Fire effects and tunnel performance: system structural response M43.

Felicetti R., 2013. "Assessment methods of fire damages in concrete tunnel linings." Fire technology, 49 (2), 509-529.

FIT, 2005. European Thematic Network Fire in tunnels, General report.

Glisic B. and Inaudi, D., 2008. Fibre optic methods for structural health monitoring.John Wiley \& Sons.

Hardy C.C., 2005. "Wildland fire hazard and risk: Problems, definitions, and context." Forest ecology and management, 211 (1), 73-82.

Ingason H., 2006. "Design fires in tunnels". In Second International Symposium Safe \& reliable tunnels. Innovative European achievements, Lausanne.

Ingason H., Li Y.Z. and Lönnermark A., 2015."Runehamar tunnel fire tests." Fire Safety Journal, 71, 134149.

K. Hill, J. Dreisbach, F. Joglar, B. Najafi, K. McGrattan, R. Peacock, and A. Hamins., 2007. Verification and Validation of Selected Fire Models for Nuclear Power Plant Applications. NUREG 1824, United States Nuclear Regulatory Commission, Washington, DC.

Kelly M., 2008. "Tunnel data.", UPTUN, Workpackage 1 Prevention, detection and monitoring D11c. 
Lai H. P., Wang S. Y. and Xie Y. L., 2014. "Experimental research on temperature field and structure performance under different lining water contents in road tunnel fire." Tunnelling and Underground Space Technology, 43, 327-335.

Lophaven S.N., Nielsen H.B. and Sndergaard J., 2002."DACE-A MATLAB Kriging Toolbox.", Tech. Rep.

MATLAB 2011a, The MathWorks, Inc., Natick, Massachusetts, United States.

Mc Grattan K., Hostikka S., Floyd J., Baum H., Rehm R., Mell W. and McDermott R., 2010. Fire Dynamics Simulator (Version 5). Technical Reference Guide. Volume 1: Mathematical model. NIST Special Publication 1018-5, Gaithersburg, MD, USA.

McGrattan K. and Hamins A., 2006."Numerical simulation of the Howard street tunnel fire." Fire technology, 42 (4), 273-281.

Moler C.B., 2008.Numerical computing with MATLAB. Siam.

NCHRP, 2011. "Design fires in road tunnels". Vol. 415. National Cooperative Highway Research Program, American Association of State Highway, and Transportation Officials.

Niels P.H., Johannes W., Joris F., Werner F., Horst H., Arnoud B., Jan B., Andre S. and Celini F., 2008. "Critical Structural and Functional Components," UPTUN.Workpackage 4 Fire effects and tunnel performance: system structural response D411.

Opstad K., Stensaas J. P. and Brandt A.W., 2006.".Development of new innovative technologies", UPTUN Workpackage 2 Fire development and mitigation measures 241.

Paya I., Yepes V., Gonzalez-Vidosa F., Hospitaler A., 2008. "Multiobjective optimization of concrete frames by simulated annealing", Computer-Aided Civil and Infrastructure Engineering, 23 (8), 596-610

Peter F. (2000), "The causes, effects \& control of real tunnel fires." International seminar on road traffic and accident data needs for the new century.

PIARC, 1999."Fire and Smoke control in Road Tunnels", PIARC technical committee on tunnel operations.

Rinaudo P., Torres B., Paya-Zaforteza I., Calderón P. A. and Sales, S., 2015a. "Evaluation of new regenerated fiber Bragg grating high-temperature sensors in an ISO 834 fire test." Fire Safety Journal, 71, 332-339.

Rinaudo P., Payá-Zaforteza I., Calderón P.A., and Loma-Osorio E., 2015b. "Use of temperature monitoring to estimate fire loads in tunnel fires. A case study on the Virgolo Tunnel". In 7th International Conference on Structural Health Monitoring of Intelligent Infrastructure, Torino, Italy.

SAFE TUNNEL, 2005.Innovative systems and frameworks for enhancing of traffic safety in road tunnels.IST-2000-28099. Final report.

Saz-Sánchez M.A., Serrano-Notivoli R., de Luis-Arrillaga M. and Longares-Aladrén L.A., 2010.

"Comparación de métodos de interpolación y de regresión para la cartografía de temperaturas máximas y mínimas absolutas: el caso de Navarra (Norte de España) en 2009." In VII Congreso AEC: Clima, ciudad y ecosistemas (in Spanish).

Stephens, Larry J., and Murray R. Spiegel, 2014. Statistics, fifth edition. McGraw-Hill, New York.

Wang G., Li Y.Q., Han L., Yu H. and Xie F., 2014."Post-fire performance evaluation method of high-rise buildings and its application in the Television Cultural Center, CCTV."8th International Conference on Structures in Fire SiF 14, Tongji University, Shanghai, China. 
Willmott C.J. and Matsuura K., 2006."On the use of dimensioned measures of error to evaluate the performance of spatial interpolators." International Journal of Geographical Information Science, 20 (1) 89102. 


\section{List of Figures}

Figure 1: Example of a sensor configuration (large red dots) and of an interpolation grid (small sky-blue dots): a) Distribution of temperature sensors within a monitored cross section, b) Unrolled tunnel surface showing the temperature sensors positions, c) 3D view.

Figure 2. Tunnel cross section

Figure 3. a) Typical HRR curve; b) HRR versus time for the modeled fire scenarios

Figure 4. Elevation of the tunnel showing the position of the fire load relative to the position of the temperature sensors.

Figure 5. Geometry of the model: a) 3D view b) Cross section detail.

Figure 6. Division of the perimeter of the tunnel cross section and nomenclature used to define the location of the sensors.

Figure 7. Layout of sensors in the tunnel cross section. Each row contains five different possible layouts, all with the same number of sensors $\mathrm{Ny}$ in each cross section. The sensors can be located every 5, 10,15 or $20 \mathrm{~m}$ along the length of the tunnel.

Figure 8.True temperatures $15 \mathrm{~min}$ after the beginning of the fire event caused by a heavy goods vehicle (fire scenario HRR 100) located in the center of the middle tunnel cross section: (a) True temperatures in the $200 \mathrm{~m}$ central portion of the tunnel; (b) Temperatures in the central cross section (section with $\mathrm{x}=0$ ); (c) Temperatures along the longitudinal axis (section with $-100 \leq x \leq 100$ ).

Figure 9.Estimated temperatures in the 200 central meters of the interpolation grid for the fire scenario HRR 100. Fire load located in the center of the cross section, time $=15 \mathrm{~min}$, sensor configuration 'ckr20', fire load in the middle of two monitored cross sections. Interpolation methods: (a)Piecewise linear, (b) nearest neighbor, (c) piecewise cubic hermite, (d) cubic spline, (e) Kriging A, and (f) Kriging B.

Figure 10. Configuration "clmr 5". Box-and-whisker plots for the error indexes obtained with each interpolation method.

Figure 11. Evaluation of the error for the configurations with 3 sensors in the cross section and a separation of $5 \mathrm{~m}$ in the longitudinal direction a) RMSE b) MAE c) MAE(RE300) d) MAE(RE600)

Figure 12. Maximum RMSE versus total number of sensors for $H R R=100,150$ and $200 \mathrm{MW}$ (in red, green and blue respectively). Dashed lines represent the Pareto front for each HRR.

Figure 13. Maximum MAE versus total number of sensors for $H R R=100,150$ and $200 \mathrm{MW}$ (in red, green and blue respectively). Dashed lines represent the Pareto front for each HRR.

Figure 14. Maximum MAE(RE300) versus total number of sensors for $H R R=100,150$ and $200 \mathrm{MW}$ (in red, green and blue respectively). Dashed lines represent the Pareto front for each HRR.

Figure15. Maximum MAE(RE600) versus total number of sensors for $H R R=100,150$ and $200 \mathrm{MW}$ (in red, green and blue respectively). Dashed lines represent the Pareto front for each HRR.

Figure 16. Bubble chart showing the percentage of cases in which a sensor configuration is Pareto optimal in accordance with Tables 2 to 4 . 
a)

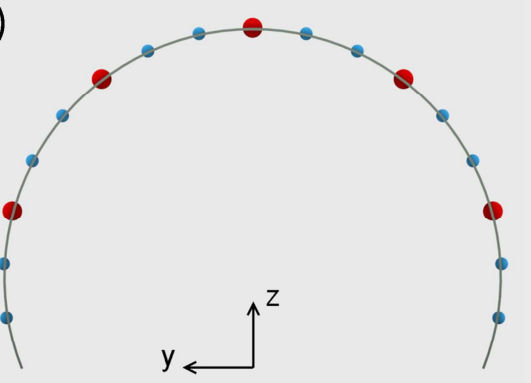

c)

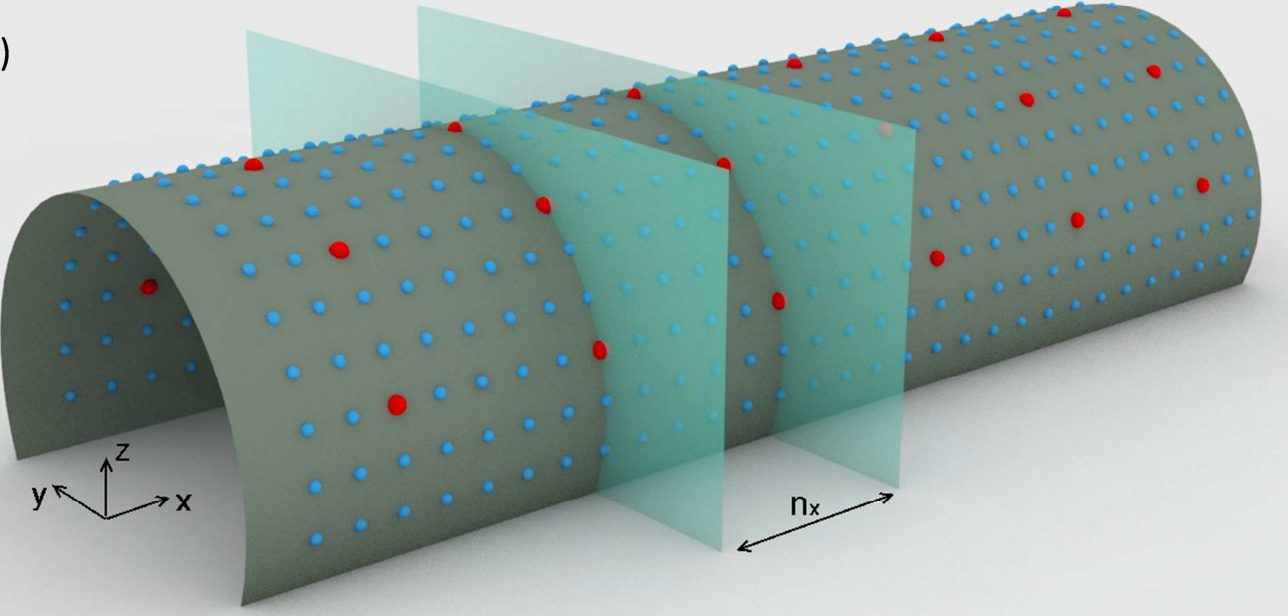

b)

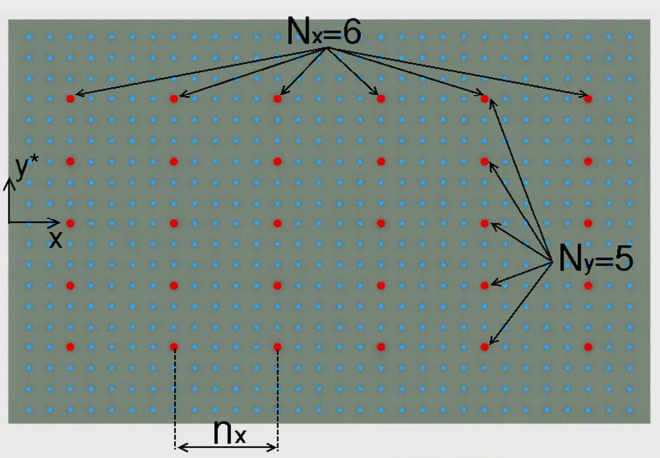

Figure 1: Example of a sensor configuration (large red dots) and of an interpolation grid (small sky-blue dots): a) Distribution of temperature sensors within a monitored cross section, b) Unrolled tunnel surface showing the temperature sensors positions, c) 3D view. 


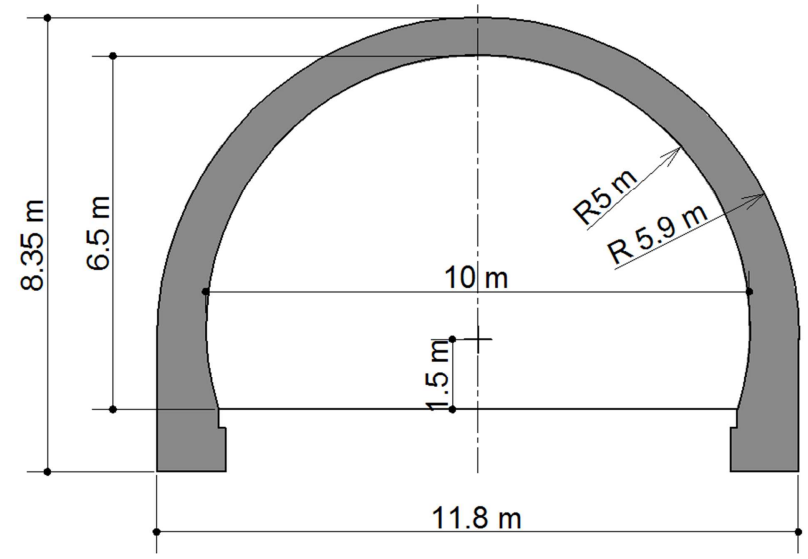

Figure 2. Tunnel cross section 

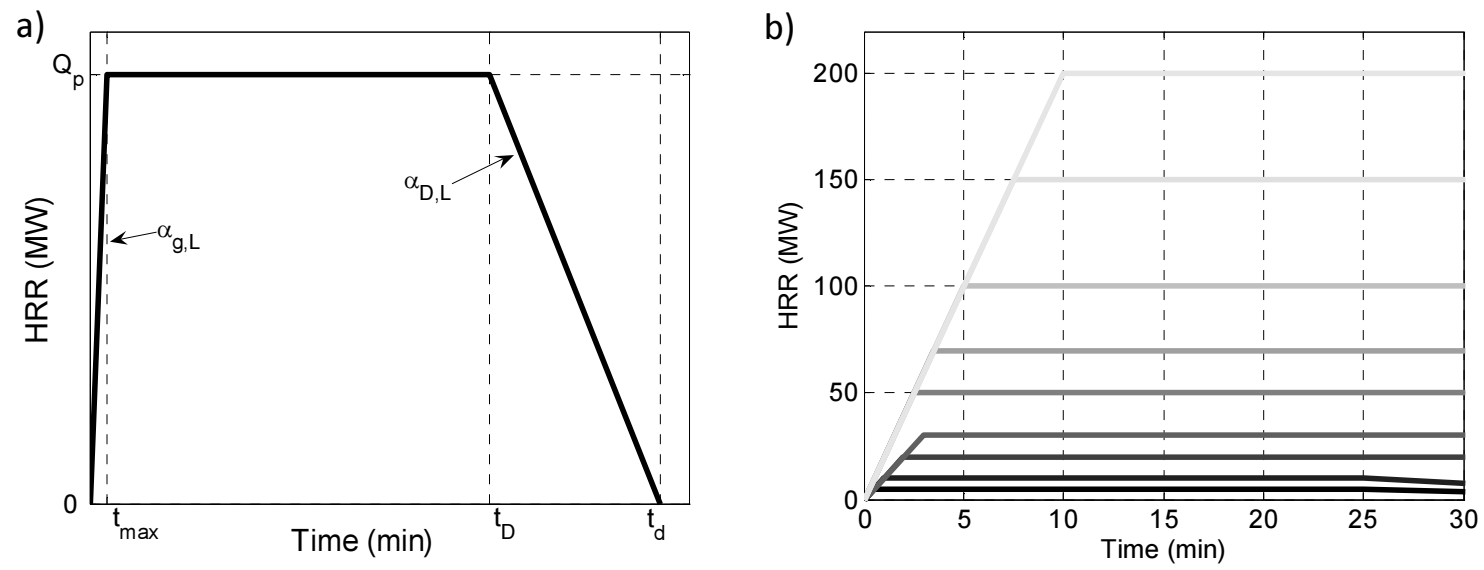

Figure 3. a) Typical HRR curve; b) HRR versus time for the modeled fire scenarios 


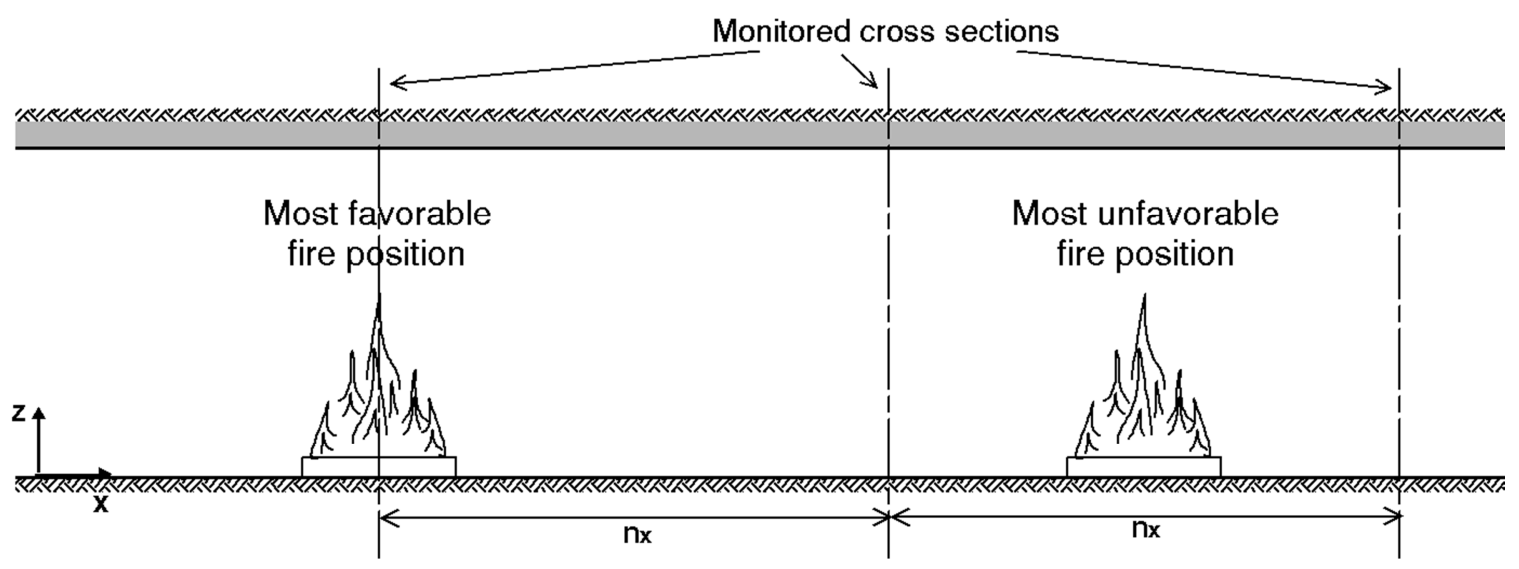

Figure 4. Elevation of the tunnel showing the position of the fire load relative to the position of the temperature sensors. 

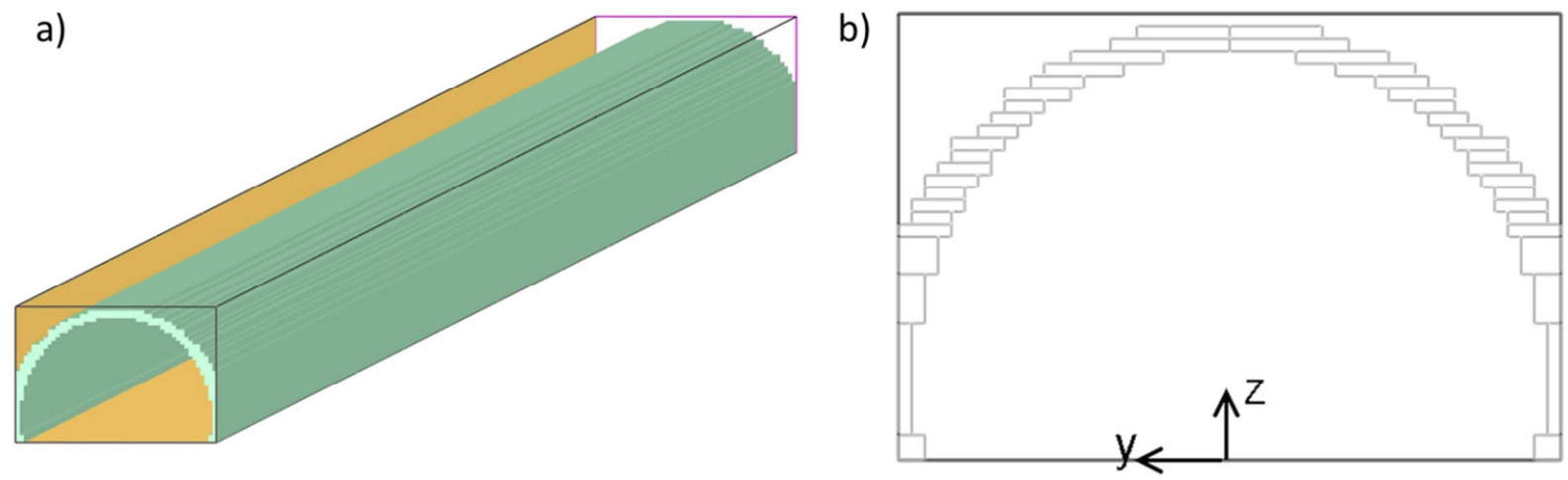

Figure 5 Geometry of the model a) 3D view b) Cross section detail 


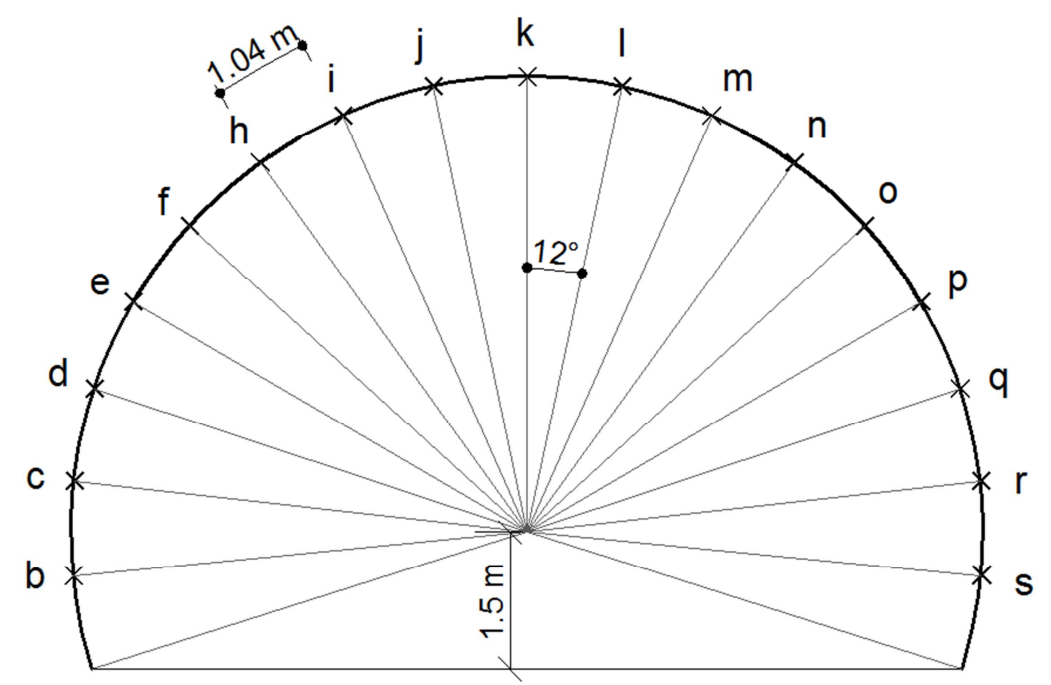

Figure 6. Division of the perimeter of the tunnel cross section and nomenclature used to define the location of the sensors. 


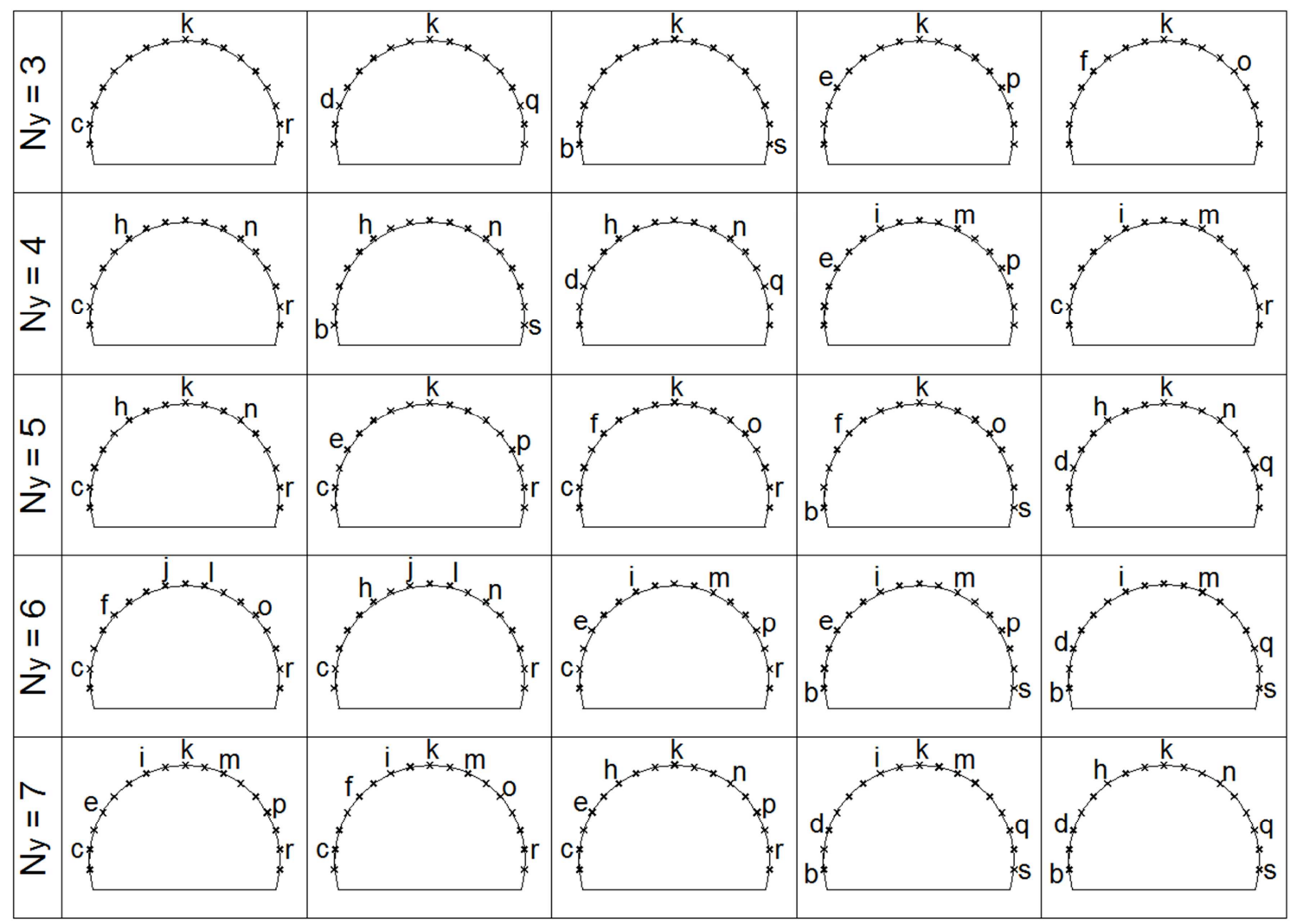

Figure 7. Layout of sensors in the tunnel cross section. Each row contains five different possible layouts, all with the same number of sensors $\mathrm{N}_{\mathrm{y}}$ in each cross section. The sensors can be located every $5,10,15$ or $20 \mathrm{~m}$ along the length of the tunnel. 
a)

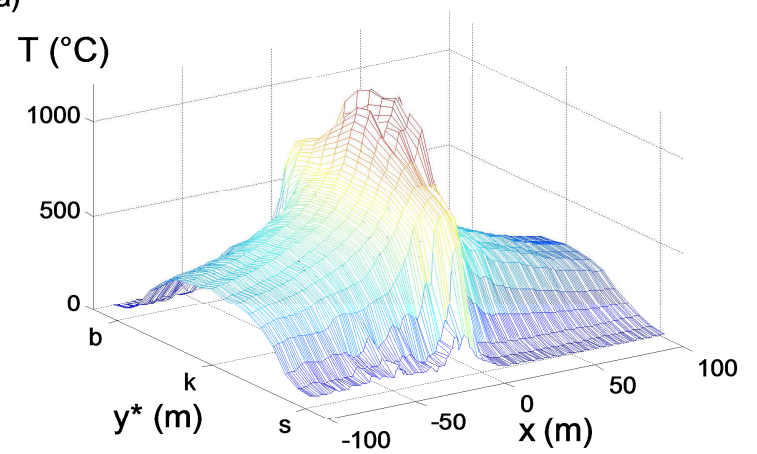

b)

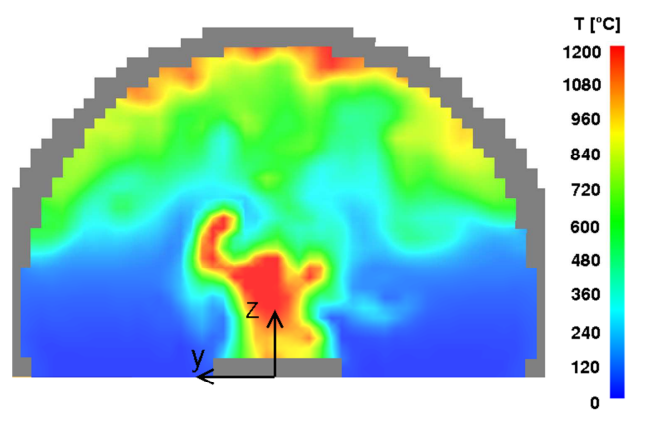

c)

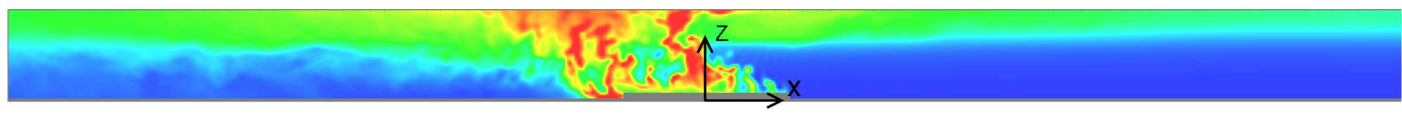

Figure 8.True temperatures $15 \mathrm{~min}$ after the beginning of the fire event caused by a heavy goods vehicle (fire scenario HRR 100) located in the center of the middle tunnel cross section: (a) True temperatures in the $200 \mathrm{~m}$ central portion of the tunnel; (b) Temperatures in the central cross section (section with $\mathrm{x}=0$ ); (c) Temperatures along the longitudinal axis (section with $100 \leq x \leq 100$ ). 
a)

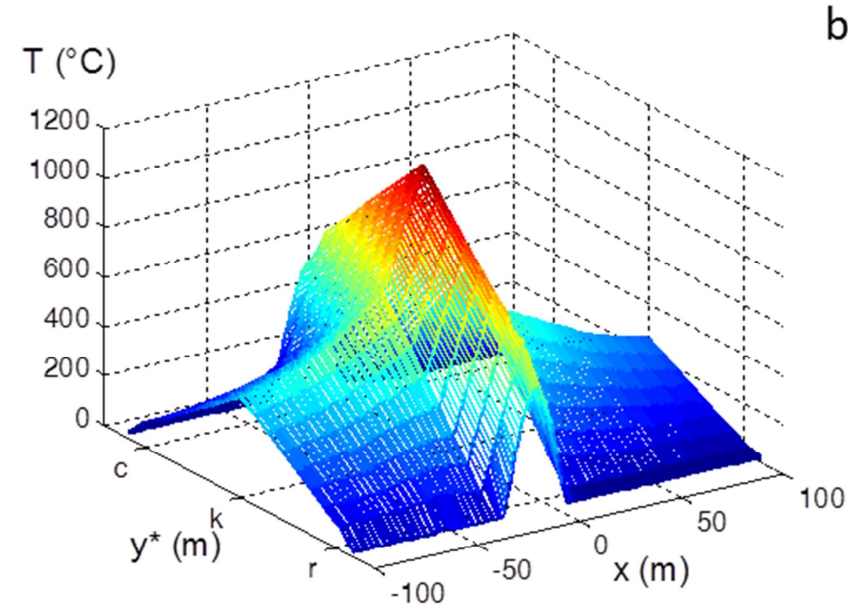

c)

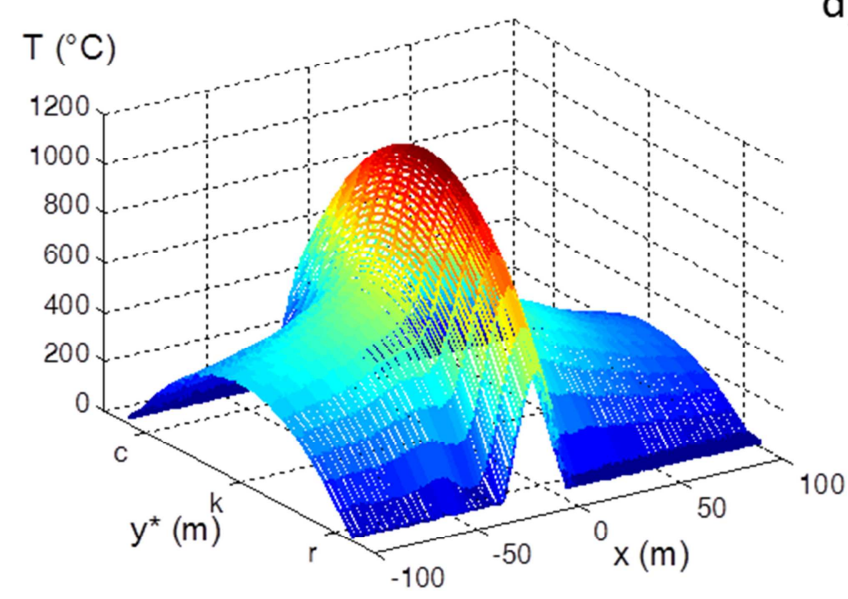

e)

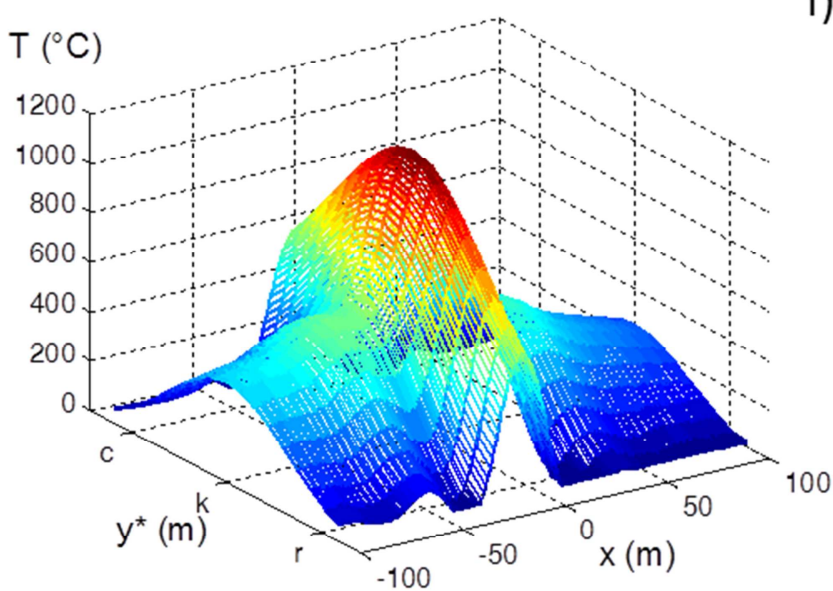

f) b)

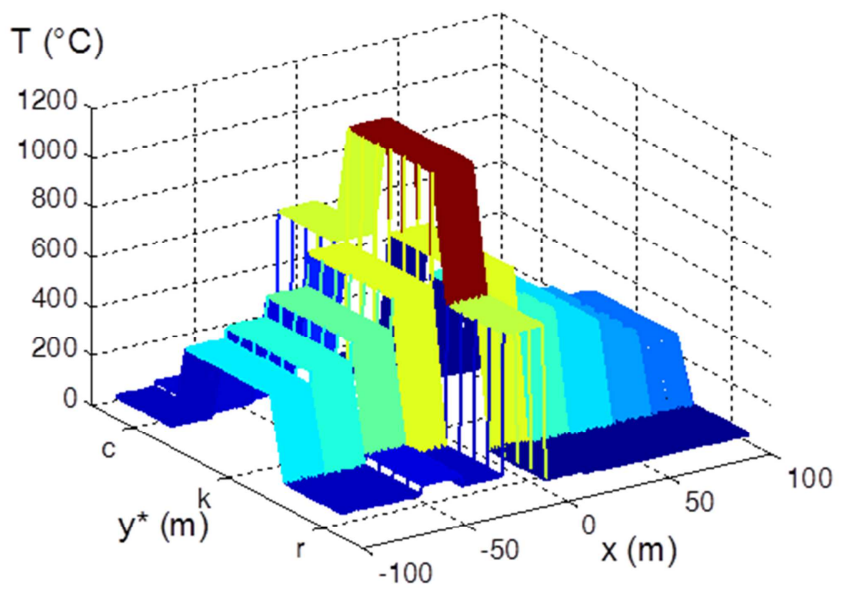

d)
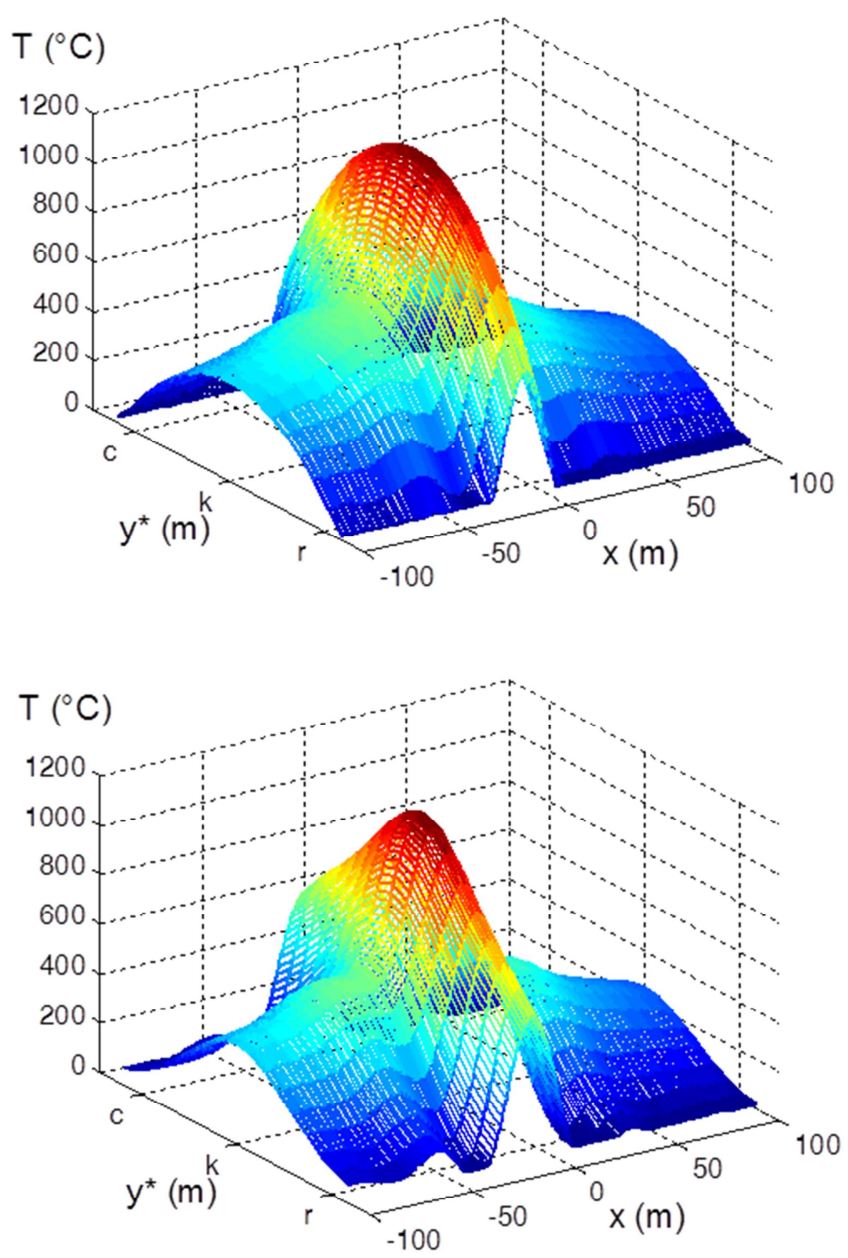

Figure 9.Estimated temperatures in the 200 central meters of the interpolation grid for the fire scenario HRR 100. Fire load located in the center of the cross section, time $=15 \mathrm{~min}$, sensor configuration 'ckr20', fire load in the middle of two monitored cross sections. Interpolation methods: (a)Piecewise linear, (b) nearest neighbor, (c) piecewise cubic hermite, (d) cubic spline, (e) Kriging A, and (f) Kriging B. 

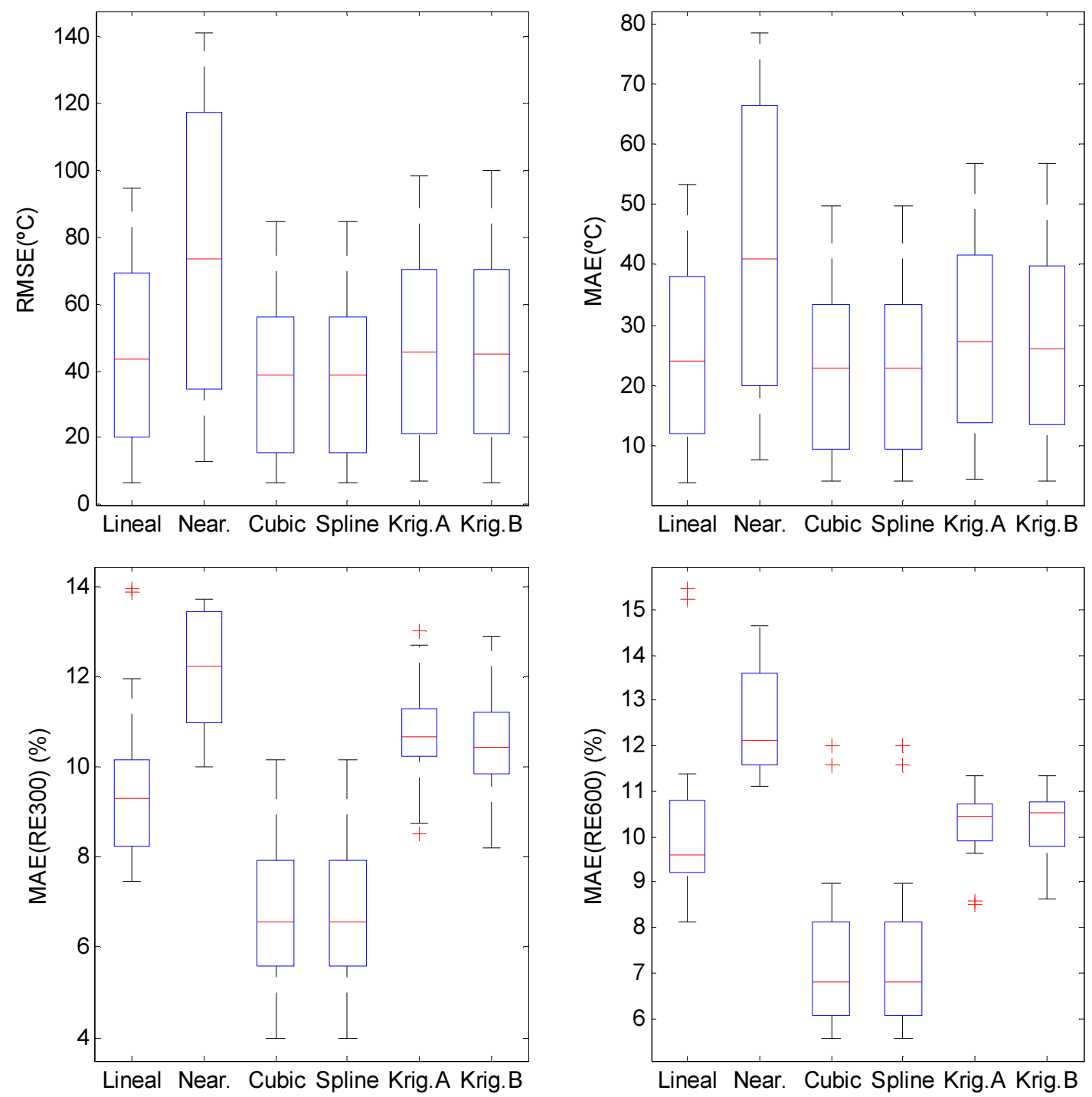

Figure 10. Configuration "Clmr 5". Box-and-whisker plots for the error indexes obtained with each interpolation method. 

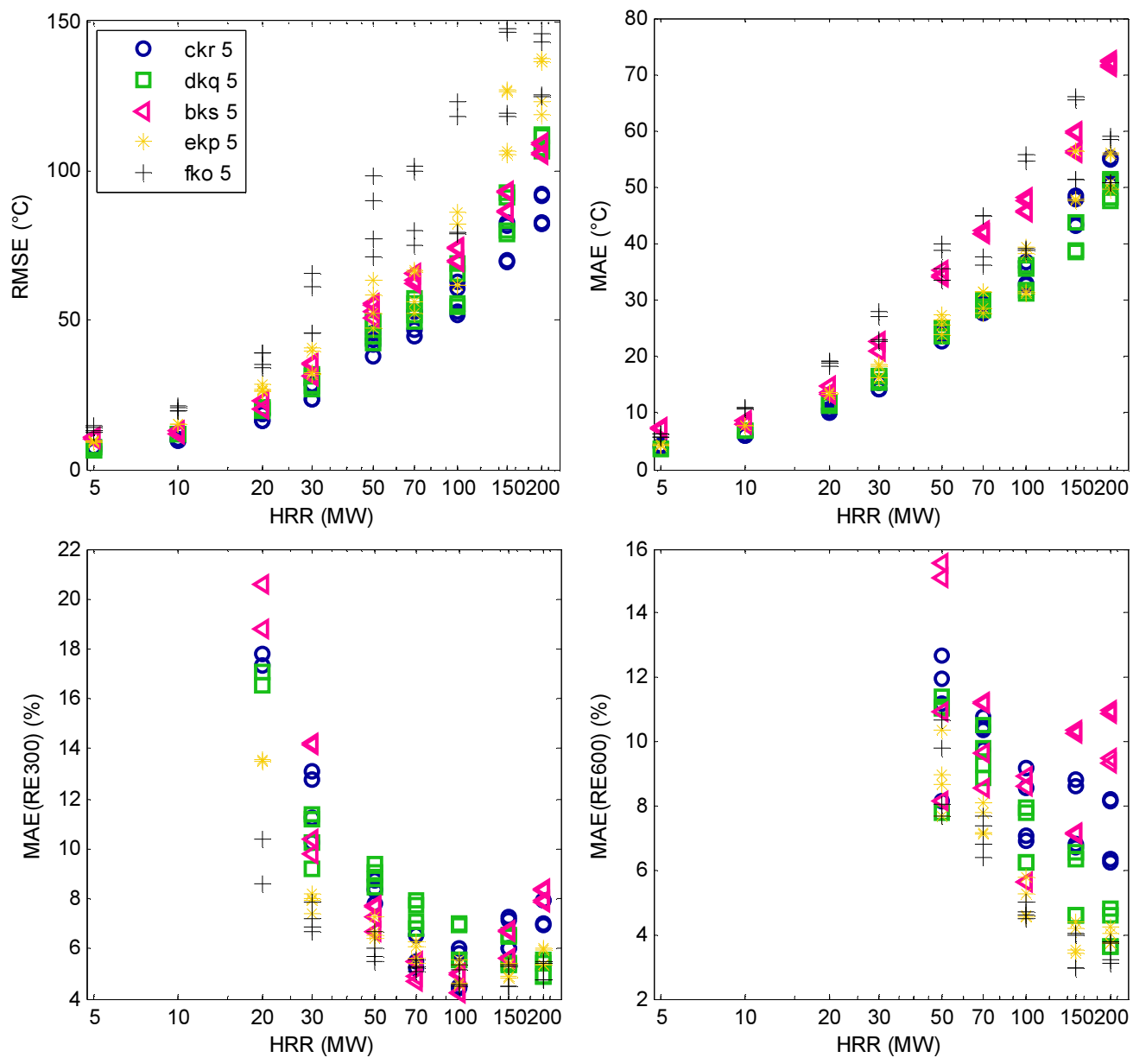

Figure 11. Evaluation of the error for the configurations with 3 sensors in the cross section and a separation of $5 \mathrm{~m}$ in the longitudinal direction a) RMSE b) MAE c) MAE(RE300) d) MAE(RE600) 


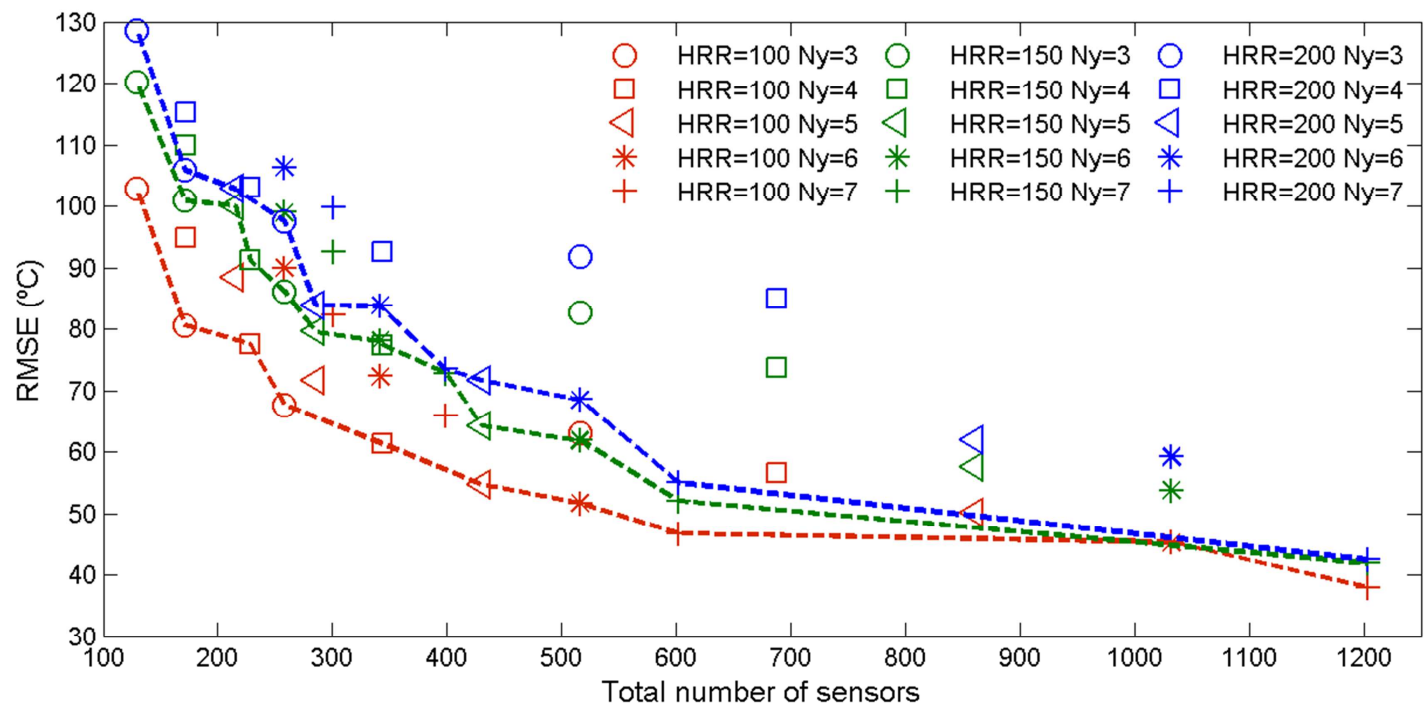

Figure 12. Maximum RMSE versus total number of sensors for HRR=100, 150 and $200 \mathrm{MW}$ (in red, green and blue respectively). Dashed lines represent the Pareto front for each HRR. 


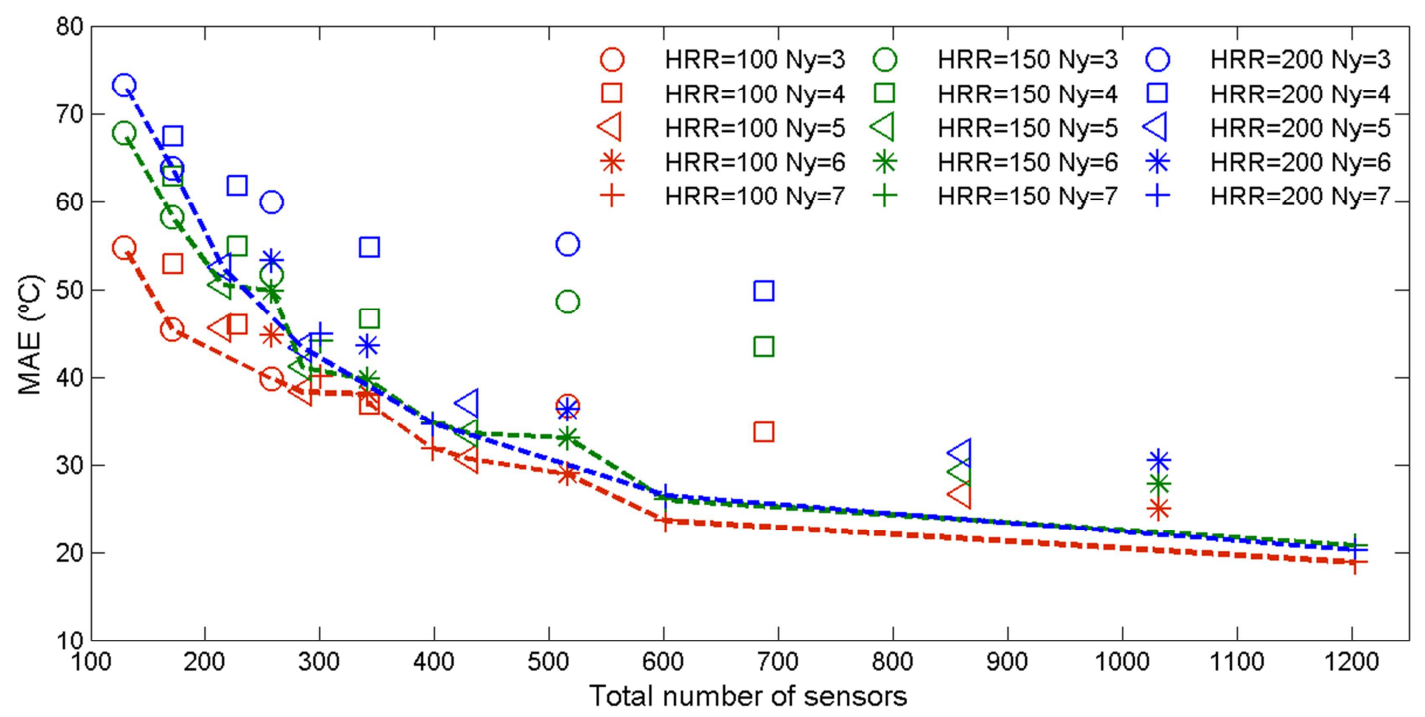

Figure 13. Maximum MAE versus total number of sensors for $H R R=100,150$ and $200 \mathrm{MW}$ (in red, green and blue respectively). Dashed lines represent the Pareto front for each HRR. 


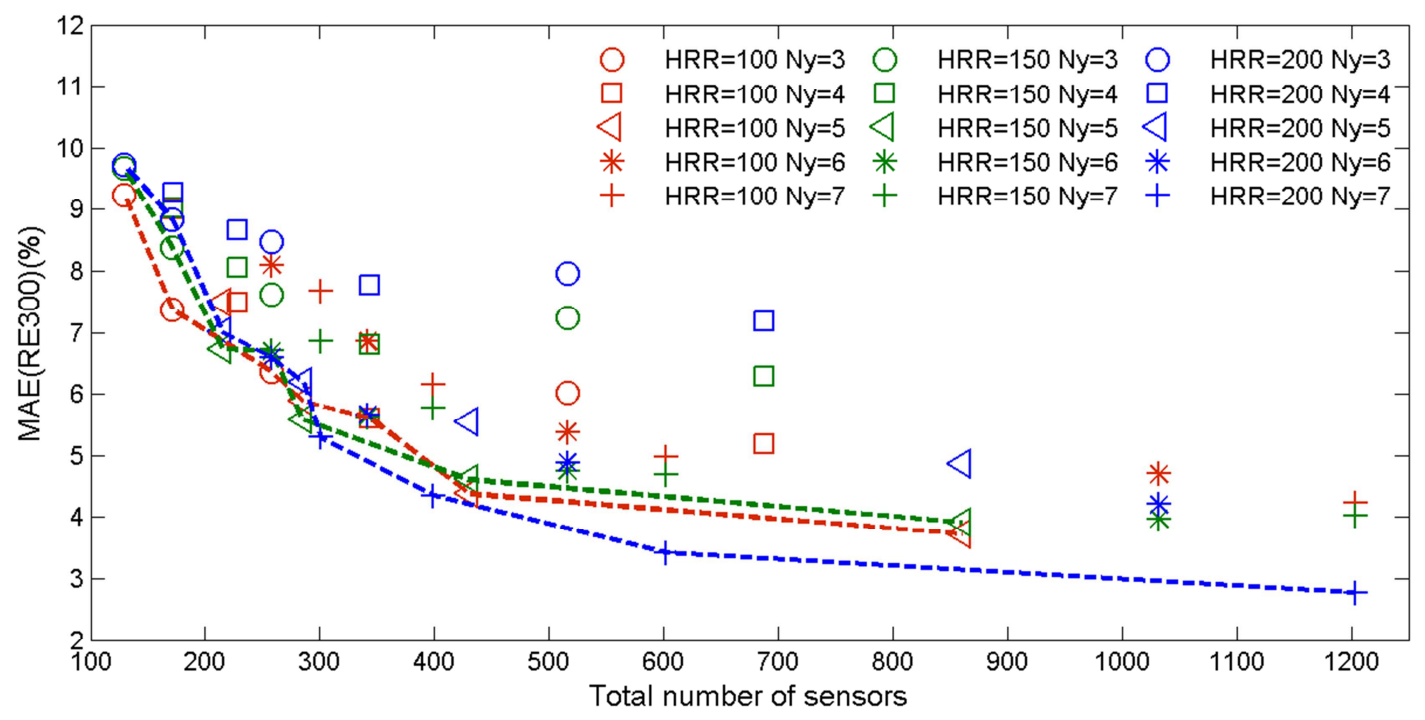

Figure 14. Maximum MAE(RE300) versus total number of sensors for $H R R=100,150$ and $200 \mathrm{MW}$ (in red, green and blue respectively). Dashed lines represent the Pareto front for each HRR. 


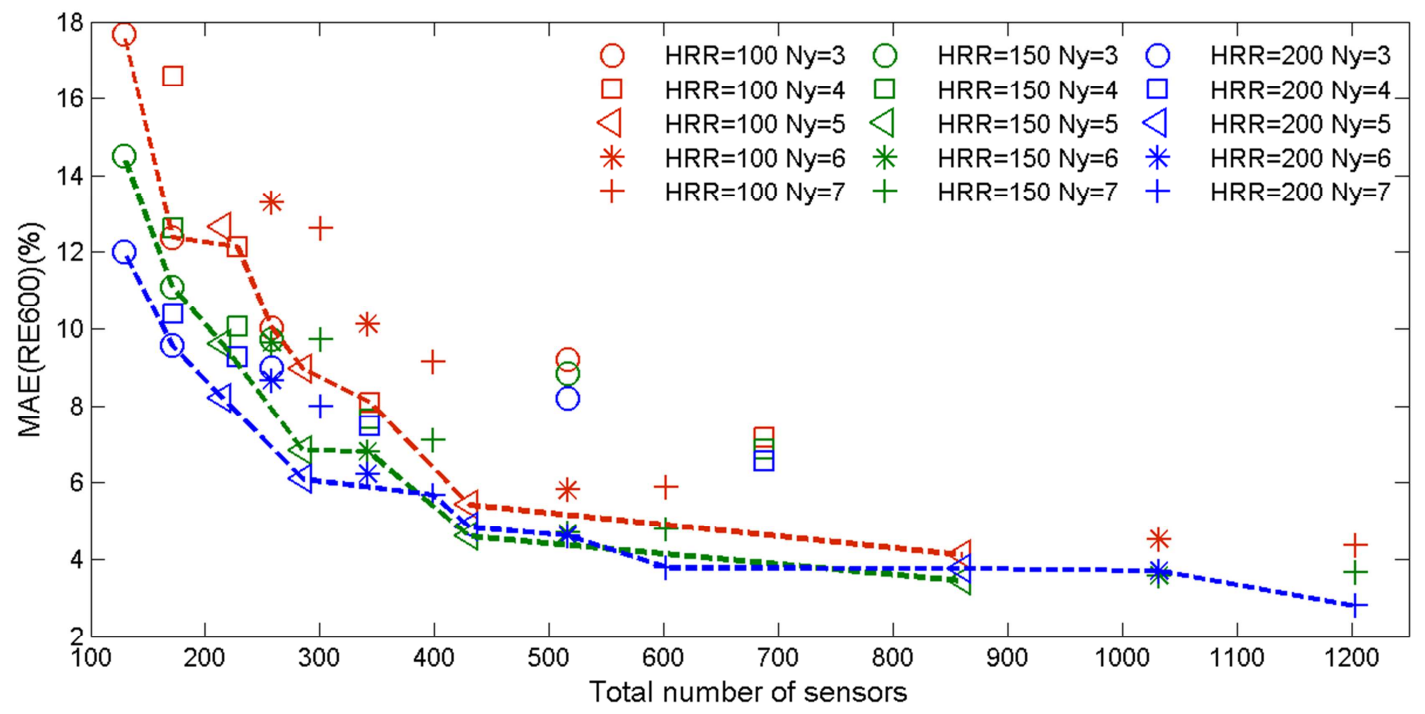

Figure 15. Maximum MAE(RE600) versus total number of sensors for HRR=100, 150 and $200 \mathrm{MW}$ (in red, green and blue respectively). Dashed lines represent the Pareto front for each HRR. 


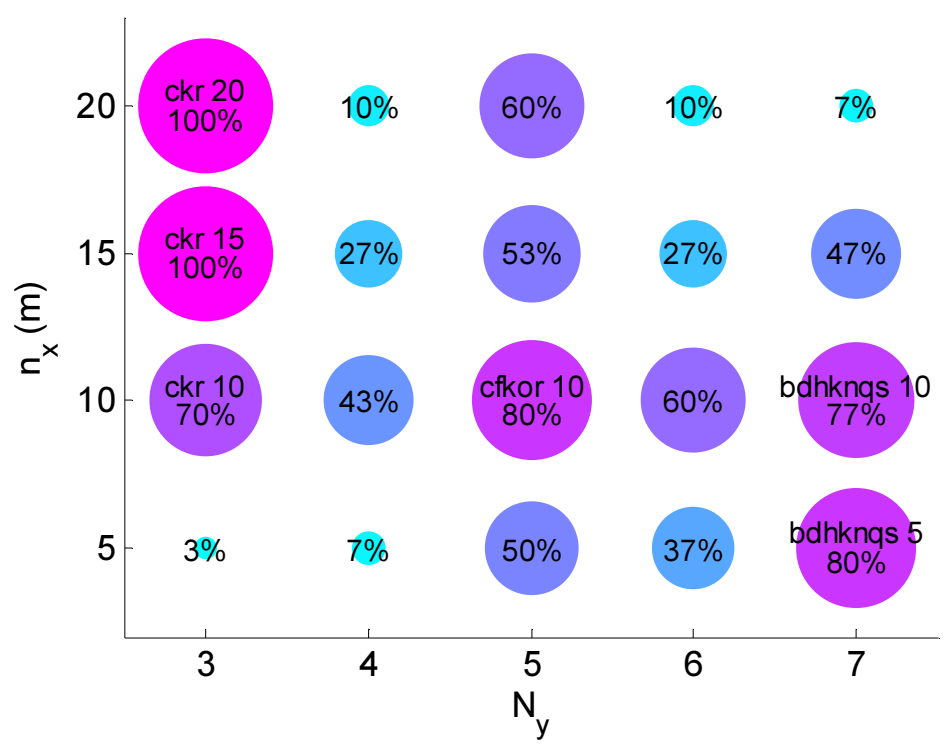

Figure 16. Bubble chart showing the percentage of cases in which a sensor configuration is Pareto optimal in accordance with Tables 2 to 4 . 


\section{List of tables}

Table 1: Fire sources. Based on Opstad et al. (2006); Inganson (2006); Caliendo et al. (2012) and PIARC (1999).

Table 2. Maximum RMSE error for the selected configurations. Pareto-optimal configurations (see Section 3.8) are in bold.

Table 3. Maximum MAE error for the selected configurations. Pareto-optimal configurations (see Section 3.8) are in bold.

Table 4. Maximum MAE(RE300) and MAE(RE600) errors for the selected configurations. Pareto-optimal configurations (see section 3.8) are in bold. 


\begin{tabular}{|c|c|c|c|c|c|c|c|c|}
\hline \multirow[b]{2}{*}{$\begin{array}{c}\text { Fire } \\
\text { scenario } \\
\text { name }\end{array}$} & \multirow[b]{2}{*}{$\begin{array}{l}\text { Road examples } \\
\text { vehicles }\end{array}$} & \multicolumn{4}{|c|}{ HRR } & \multicolumn{3}{|c|}{ Fire load geometry } \\
\hline & & $\begin{array}{c}Q_{p} \\
(M W)\end{array}$ & $\begin{array}{l}t_{\max } \\
(\min )\end{array}$ & $t_{D}(\min )$ & $\begin{array}{c}t_{d} \\
(\min )\end{array}$ & $\begin{array}{l}\text { Length } \\
\text { (m) }\end{array}$ & $\begin{array}{l}\text { Width } \\
\text { (m) }\end{array}$ & $\begin{array}{c}\text { Vertical } \\
\text { Distance } \\
\text { from road } \\
\text { pavement }\end{array}$ \\
\hline HRR 5 & 1-2 cars & 5 & 0.5 & 25 & 45 & 6 & 2 & 0.2 \\
\hline HRR 10 & Small van, $2-3$ cars & 10 & 1 & 25 & 45 & 12 & 2 & 0.2 \\
\hline HRR 20 & $\begin{array}{l}\text { Big van, public bus, } \\
\text { multiple vehicles }\end{array}$ & 20 & 2 & 35 & 55 & 12 & 2.5 & 0.2 \\
\hline HRR 30 & Bus, empty HGV & 30 & 3 & 70 & 100 & 12 & 2.5 & 0.4 \\
\hline HRR 50 & $\begin{array}{c}\text { Combustible load on } \\
\text { truck }\end{array}$ & 50 & 2.5 & 70 & 100 & 12 & 2.5 & 0.4 \\
\hline HRR 70 & $\begin{array}{l}\text { HGV load with } \\
\text { combustibles }\end{array}$ & 70 & 3.5 & 70 & 100 & 12 & 2.5 & 0.4 \\
\hline HRR 100 & HGV (average) & 100 & 5 & 70 & 100 & 12 & 2.5 & 0.4 \\
\hline HRR 150 & $\begin{array}{l}\text { Load with easy } \\
\text { combustion HGV }\end{array}$ & 150 & 7.5 & 70 & 100 & 12 & 2.5 & 0.4 \\
\hline HRR 200 & $\begin{array}{c}\text { Limited by oxygen, } \\
\text { petrol tanker, } \\
\text { multiple HGVs }\end{array}$ & 200 & 10 & 70 & 100 & 12 & 2.5 & 0.4 \\
\hline
\end{tabular}

Table 1. Fire sources. Based on Opstad et al. (2006); Inganson (2006); Caliendo et al. (2012) and PIARC (1999). 


\begin{tabular}{|c|c|c|c|c|c|c|c|c|c|c|}
\hline \multirow[b]{2}{*}{ Configuration } & \multirow{2}{*}{$\begin{array}{c}\text { Total } \\
\text { number of } \\
\text { sensors }\end{array}$} & \multicolumn{9}{|c|}{ RMSE } \\
\hline & & HRR 5 & $\begin{array}{c}\text { HRR } \\
10\end{array}$ & $\begin{array}{c}\text { HRR } \\
20\end{array}$ & $\begin{array}{c}\text { HRR } \\
30\end{array}$ & $\begin{array}{c}\text { HRR } \\
50\end{array}$ & $\begin{array}{c}\text { HRR } \\
70\end{array}$ & $\begin{array}{l}\text { HRR } \\
100\end{array}$ & $\begin{array}{c}\text { HRR } \\
150\end{array}$ & $\begin{array}{c}\text { HRR } \\
200\end{array}$ \\
\hline ckr 20 & 129 & 9.2 & 13.4 & 26.7 & 41.2 & 68.8 & 82.2 & 102.8 & 120.1 & 128.6 \\
\hline ckr 15 & 171 & 8.4 & 12.5 & 24.1 & 38.4 & 61.8 & 71.7 & 80.5 & 100.9 & 105.9 \\
\hline chnr 20 & 172 & 9.9 & 13.5 & 24.7 & 39.0 & 64.4 & 82.2 & 94.9 & 109.8 & 115.2 \\
\hline cfkor 20 & 215 & 8.8 & 12.4 & 23.5 & 36.2 & 62.2 & 77.0 & 88.3 & 100.0 & 102.8 \\
\hline chnr 15 & 228 & 9.0 & 12.5 & 22.9 & 37.6 & 58.5 & 71.4 & 77.6 & 91.2 & 103.0 \\
\hline ckr 10 & 258 & 7.8 & 11.1 & 19.8 & 32.1 & 48.5 & 55.7 & 67.7 & 86.2 & 97.5 \\
\hline ceimpr 20 & 258 & 8.7 & 12.6 & 23.3 & 35.7 & 62.7 & 74.8 & 89.9 & 99.0 & 106.4 \\
\hline cfkor 15 & 285 & 8.1 & 11.6 & 21.1 & 35.6 & 58.5 & 66.4 & 71.7 & 79.6 & 83.9 \\
\hline bdhknqs 20 & 301 & 8.0 & 12.4 & 22.0 & 34.3 & 55.8 & 71.3 & 82.4 & 92.5 & 99.9 \\
\hline ceimpr 15 & 342 & 8.0 & 11.2 & 21.6 & 33.4 & 59.5 & 67.0 & 72.3 & 78.1 & 83.8 \\
\hline cimr 10 & 344 & 7.9 & 10.7 & 19.0 & 30.8 & 47.8 & 56.4 & 61.3 & 77.4 & 92.6 \\
\hline bdhknqs 15 & 399 & 7.1 & 10.9 & 20.5 & 31.0 & 51.0 & 61.1 & 65.8 & 72.8 & 73.4 \\
\hline cfkor 10 & 430 & 7.4 & 9.9 & 17.5 & 27.2 & 43.3 & 53.2 & 54.7 & 64.3 & 71.7 \\
\hline ckr 5 & 516 & 7.5 & 10.4 & 18.6 & 28.4 & 45.8 & 53.0 & 63.0 & 82.7 & 91.9 \\
\hline ceimpr 10 & 516 & 7.1 & 9.7 & 17.1 & 26.4 & 43.0 & 48.2 & 51.7 & 61.9 & 68.5 \\
\hline bdhknqs 10 & 602 & 6.2 & 9.5 & 16.4 & 24.2 & 37.6 & 42.8 & 46.7 & 52.0 & 55.0 \\
\hline $\operatorname{cimr} 5$ & 688 & 7.4 & 9.5 & 17.0 & 26.5 & 42.2 & 51.1 & 56.5 & 73.7 & 85.0 \\
\hline cfkor 5 & 860 & 6.9 & 8.5 & 15.0 & 22.5 & 37.9 & 46.2 & 50.2 & 57.5 & 62.0 \\
\hline ceimpr 5 & 1032 & 6.4 & 8.3 & 14.6 & 20.7 & 34.5 & 41.4 & 45.3 & 53.7 & 59.2 \\
\hline bdhknqs 5 & 1204 & 5.2 & 7.8 & 13.1 & 18.1 & 28.7 & 34.0 & 38.0 & 41.8 & 42.4 \\
\hline
\end{tabular}

Table 2. Maximum RMSE error for the selected configurations. Pareto-optimal configurations (see Section 3.8) are in bold. 


\begin{tabular}{|c|c|c|c|c|c|c|c|c|c|c|}
\hline \multirow[b]{2}{*}{ Configuration } & \multirow{2}{*}{$\begin{array}{c}\text { Total } \\
\text { number of } \\
\text { sensors }\end{array}$} & \multicolumn{9}{|c|}{ MAE } \\
\hline & & HRR 5 & $\begin{array}{c}\text { HRR } \\
10\end{array}$ & $\begin{array}{c}\text { HRR } \\
20\end{array}$ & $\begin{array}{c}\text { HRR } \\
30\end{array}$ & $\begin{array}{c}\text { HRR } \\
50\end{array}$ & $\begin{array}{c}\text { HRR } \\
70\end{array}$ & $\begin{array}{c}\text { HRR } \\
100\end{array}$ & $\begin{array}{c}\text { HRR } \\
150\end{array}$ & $\begin{array}{c}\text { HRR } \\
200\end{array}$ \\
\hline ckr 20 & 129 & 5.1 & 7.6 & 14.4 & 21.0 & 34.6 & 42.7 & 54.7 & 67.8 & 73.3 \\
\hline ckr 15 & 171 & 4.9 & 7.2 & 13.1 & 19.3 & 30.8 & 37.1 & 45.3 & 58.2 & 63.7 \\
\hline chnr 20 & 172 & 5.9 & 7.9 & 14.1 & 21.8 & 35.3 & 45.7 & 52.8 & 62.9 & 67.4 \\
\hline cfkor 20 & 215 & 5.1 & 6.9 & 12.4 & 18.7 & 30.6 & 39.0 & 45.6 & 50.5 & 52.5 \\
\hline chnr 15 & 228 & 5.4 & 7.3 & 13.2 & 20.8 & 32.4 & 40.0 & 45.9 & 54.9 & 61.8 \\
\hline ckr 10 & 258 & 4.6 & 6.6 & 11.4 & 17.0 & 25.8 & 31.8 & 39.8 & 51.7 & 59.9 \\
\hline ceimpr 20 & 258 & 4.9 & 7.0 & 12.1 & 18.5 & 30.2 & 38.1 & 44.7 & 49.8 & 53.3 \\
\hline cfkor 15 & 285 & 4.7 & 6.4 & 11.3 & 18.1 & 28.3 & 33.4 & 38.3 & 41.1 & 43.3 \\
\hline bdhknqs 20 & 301 & 3.9 & 6.9 & 11.8 & 17.3 & 26.6 & 33.4 & 40.1 & 44.1 & 44.9 \\
\hline ceimpr 15 & 342 & 4.7 & 6.2 & 11.1 & 17.1 & 27.3 & 32.6 & 38.1 & 39.8 & 43.6 \\
\hline cimr 10 & 344 & 4.8 & 6.4 & 11.1 & 17.0 & 26.7 & 32.8 & 36.8 & 46.6 & 54.8 \\
\hline bdhknqs 15 & 399 & 3.6 & 6.1 & 10.7 & 15.2 & 23.1 & 27.5 & 31.7 & 34.7 & 34.7 \\
\hline cfkor 10 & 430 & 4.2 & 5.7 & 9.7 & 14.6 & 23.0 & 28.3 & 30.6 & 33.6 & 37.0 \\
\hline ckr 5 & 516 & 4.4 & 6.2 & 10.7 & 15.5 & 24.2 & 29.9 & 36.7 & 48.6 & 55.2 \\
\hline ceimpr 10 & 516 & 4.1 & 5.6 & 9.3 & 14.0 & 21.9 & 26.2 & 29.0 & 33.1 & 36.3 \\
\hline bdhknqs 10 & 602 & 3.1 & 5.4 & 8.9 & 12.2 & 18.0 & 21.0 & 23.6 & 26.0 & 26.5 \\
\hline $\operatorname{cimr} 5$ & 688 & 4.5 & 5.8 & 9.9 & 15.0 & 23.5 & 29.2 & 33.7 & 43.4 & 49.8 \\
\hline cfkor 5 & 860 & 3.9 & 5.0 & 8.4 & 12.5 & 20.1 & 24.4 & 26.6 & 29.2 & 31.3 \\
\hline ceimpr 5 & 1032 & 3.7 & 4.7 & 7.9 & 11.5 & 18.1 & 22.2 & 25.0 & 27.8 & 30.4 \\
\hline bdhkngs 5 & 1204 & 2.7 & 4.5 & 7.2 & 9.7 & 14.2 & 16.6 & 18.8 & 20.7 & 20.2 \\
\hline
\end{tabular}

Table 3. Maximum MAE error for the selected configurations. Pareto-optimal configurations (see Section 3.8) are in bold. 


\begin{tabular}{|c|c|c|c|c|c|c|c|c|c|c|c|c|c|}
\hline \multirow[b]{2}{*}{ Configuration } & \multirow{2}{*}{$\begin{array}{c}\text { Total } \\
\text { number } \\
\text { of } \\
\text { sensors }\end{array}$} & \multicolumn{7}{|c|}{ MAE (RE300) } & \multicolumn{5}{|c|}{ MAE (RE600) } \\
\hline & & $\begin{array}{c}\text { HRR } \\
20\end{array}$ & $\begin{array}{c}\text { HRR } \\
30\end{array}$ & $\begin{array}{c}\text { HRR } \\
50\end{array}$ & $\begin{array}{c}\text { HRR } \\
70\end{array}$ & $\begin{array}{c}\text { HRR } \\
100\end{array}$ & $\begin{array}{l}\text { HRR } \\
150 \\
\end{array}$ & $\begin{array}{l}\text { HRR } \\
200\end{array}$ & $\begin{array}{c}\text { HRR } \\
50\end{array}$ & $\begin{array}{c}\text { HRR } \\
70 \\
\end{array}$ & $\begin{array}{c}\text { HRR } \\
100\end{array}$ & $\begin{array}{c}\text { HRR } \\
150\end{array}$ & $\begin{array}{l}\text { HRR } \\
200\end{array}$ \\
\hline ckr 20 & 129 & 31.1 & 22.6 & 13.2 & 10.3 & 9.2 & 9.7 & 9.7 & 27.5 & 21.7 & 17.7 & 14.5 & 12.0 \\
\hline ckr 15 & 171 & 29.7 & 19.1 & 11.5 & 8.6 & 7.4 & 8.4 & 8.8 & 24.2 & 16.8 & 12.4 & 11.1 & 9.6 \\
\hline chnr 20 & 172 & 18.9 & 17.8 & 13.5 & 10.7 & 9.0 & 9.0 & 9.3 & 15.8 & 16.9 & 16.6 & 12.6 & 10.4 \\
\hline cfkor 20 & 215 & 27.7 & 13.7 & 9.9 & 8.3 & 7.5 & 6.7 & 7.0 & 23.3 & 14.3 & 12.6 & 9.6 & 8.2 \\
\hline chnr 15 & 228 & 17.1 & 15.4 & 12.0 & 9.4 & 7.5 & 8.0 & 8.7 & 13.9 & 15.2 & 12.1 & 10.1 & 9.3 \\
\hline ckr 10 & 258 & 21.5 & 14.8 & 9.0 & 6.9 & 6.4 & 7.6 & 8.5 & 15.3 & 11.3 & 10.0 & 9.7 & 9.0 \\
\hline ceimpr 20 & 258 & 25.2 & 13.6 & 10.6 & 9.6 & 8.1 & 6.7 & 6.6 & 21.6 & 14.7 & 13.3 & 9.6 & 8.7 \\
\hline cfkor 15 & 285 & 24.5 & 11.8 & 8.4 & 6.9 & 5.9 & 5.6 & 6.2 & 18.7 & 11.9 & 9.0 & 6.8 & 6.1 \\
\hline bdhknqs 20 & 301 & 20.5 & 13.9 & 10.3 & 9.1 & 7.7 & 6.9 & 5.3 & 19.8 & 15.5 & 12.6 & 9.7 & 8.0 \\
\hline ceimpr 15 & 342 & 23.8 & 11.2 & 9.3 & 8.2 & 6.9 & 5.6 & 5.7 & 21.0 & 12.9 & 10.1 & 6.8 & 6.2 \\
\hline cimr 10 & 344 & 11.4 & 12.8 & 9.1 & 6.9 & 5.6 & 6.8 & 7.8 & 15.5 & 10.6 & 8.1 & 7.7 & 7.5 \\
\hline bdhknqs 15 & 399 & 19.9 & 11.8 & 8.7 & 7.2 & 6.2 & 5.8 & 4.4 & 17.0 & 11.5 & 9.1 & 7.1 & 5.7 \\
\hline cfkor 10 & 430 & 10.7 & 8.5 & 6.3 & 5.3 & 4.4 & 4.6 & 5.5 & 14.9 & 9.4 & 5.4 & 4.6 & 4.8 \\
\hline ckr 5 & 516 & 17.8 & 13.1 & 8.7 & 6.6 & 6.0 & 7.2 & 8.0 & 12.7 & 10.8 & 9.2 & 8.8 & 8.2 \\
\hline ceimpr 10 & 516 & 11.6 & 8.6 & 7.2 & 6.5 & 5.4 & 4.7 & 4.9 & 16.6 & 8.0 & 5.8 & 4.7 & 4.6 \\
\hline bdhknqs 10 & 602 & 9.5 & 8.4 & 6.6 & 5.8 & 5.0 & 4.7 & 3.4 & 15.9 & 7.6 & 5.9 & 4.8 & 3.8 \\
\hline $\operatorname{cimr} 5$ & 688 & 8.7 & 10.2 & 7.9 & 6.1 & 5.2 & 6.3 & 7.2 & 12.0 & 9.0 & 7.2 & 6.9 & 6.5 \\
\hline cfkor 5 & 860 & 8.1 & 6.5 & 5.1 & 4.2 & 3.7 & 3.9 & 4.9 & 9.1 & 6.7 & 4.1 & 3.4 & 3.8 \\
\hline ceimpr 5 & 1032 & 8.0 & 6.8 & 6.2 & 5.6 & 4.7 & 4.0 & 4.2 & 13.8 & 6.7 & 4.5 & 3.6 & 3.7 \\
\hline bdhknqs 5 & 1204 & 6.6 & 6.2 & 5.5 & 4.7 & 4.2 & 4.0 & 2.8 & 8.2 & 5.8 & 4.4 & 3.7 & 2.8 \\
\hline
\end{tabular}

Table 4. Maximum MAE(RE300) and MAE(RE600) errors for the selected configurations. Pareto-optimal configurations (see section 3.8) are in bold. 